\title{
An optimal energy management system for a commercial building with renewable energy generation under real-time electricity prices
}

\author{
Nsilulu T. Mbungu ${ }^{1,2}$, Ramesh. C. Bansal ${ }^{1}$, R. Naidoo ${ }^{1}$, V. Miranda ${ }^{2}$, and M. Bipath ${ }^{3}$ \\ ${ }^{1}$ Department of Electrical, Electronics and Computer Engineering, University of Pretoria, South Africa, \\ ${ }^{2}$ Faculty of Engenharia, University of Porto, and INESC - Instituto de Engenharia de Sistemas e \\ Computadores do Porto, Porto, Portugal \\ ${ }^{3}$ SANEDI: Smart Grids, Johannesburg, South Africa \\ Email: mbungunsilulu@gmail.com,rcbansal@ieee.org,Raj.Naidoo@up.ac.za, \\ vladimiro.miranda@inesctec.pt, and minnesh.bipath@sanedi.org.za
}

\section{Highlights}

- Develops a real-time electricity pricing structure in conjunction with TOU electricity tariff.

- Develops an adaptive strategy in the framework of the smart grid using MPC design.

- Develops a new approach to optimization of the cost of energy in real-time electricity pricing environment.

- Designs an optimal strategy for integrating PV with battery storage to the grid in realtime electricity pricing scheme.

- Gives the consumer an opportunity to deal with the cost of electricity usage. 
Abstract- This paper presents an approach to the energy management and control of the effective cost of energy in real-time electricity pricing environment. The strategy aims to optimise the overall energy flow in the electrical system that minimises the cost of power consumption from the grid. To substantiate these claims different cases of time-of-use (TOU) and renewable energy electricity tariff, i.e. in summer and winter seasons, and the robustness of system is analysed. A given energy demand for commercial usage in the city of Tshwane (South Africa) is used to investigate the behaviour of the designed method during low and high demand periods. As grid integrated renewable energy resources, photovoltaic $(\mathrm{PV})$ is an important consideration in assuring excellent power supply and environmental issues in the commercial building. An adaptive optimal approach in the framework of model predictive control (MPC) is designed to coordinate the energy flow on the electrical system. The results show that the proposed adaptive MPC strategy can promote the new approach of an optimal electrical system design, which reduces the energy cost to pay the utility grid by about $46 \%$ or more depending on the set target.

Index Terms - Battery bank, Energy management, Model predictive control, Photovoltaic, Smart grid, Time-of-use tariff.

NOMENCLATURE

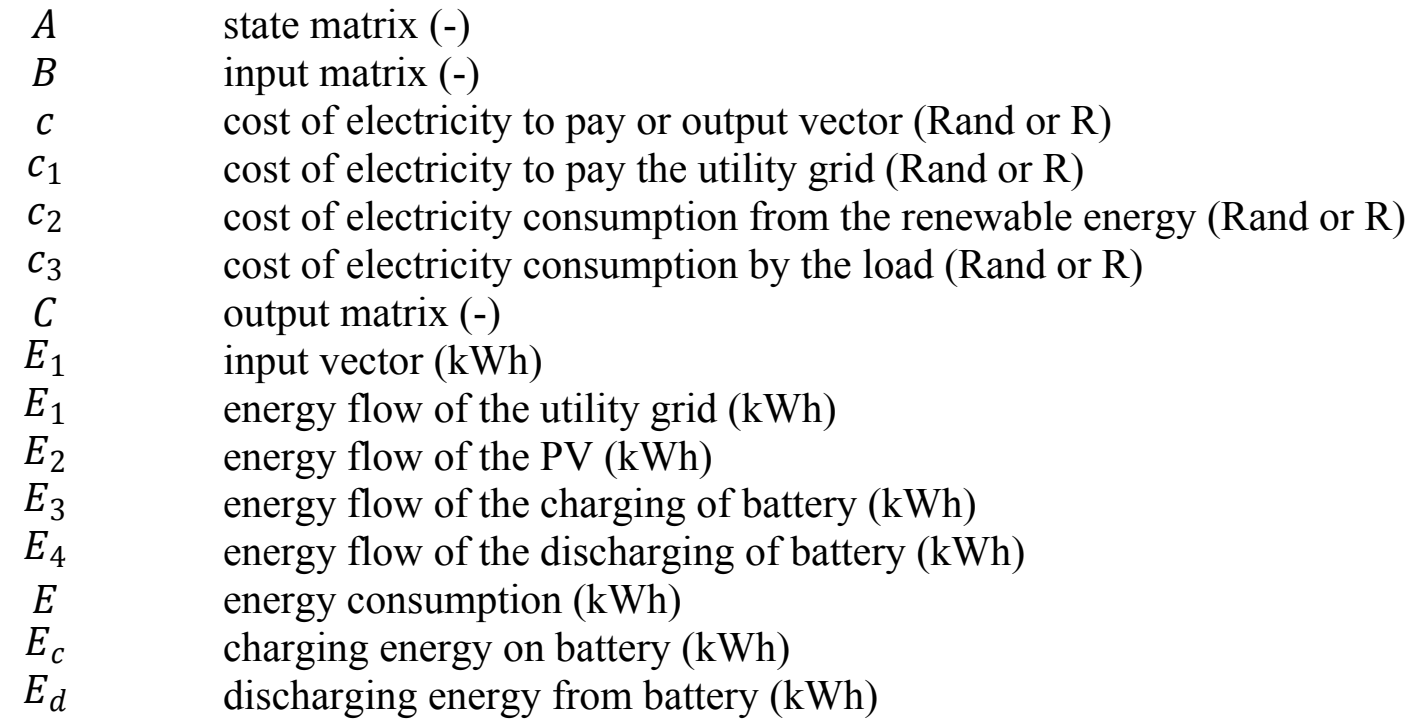




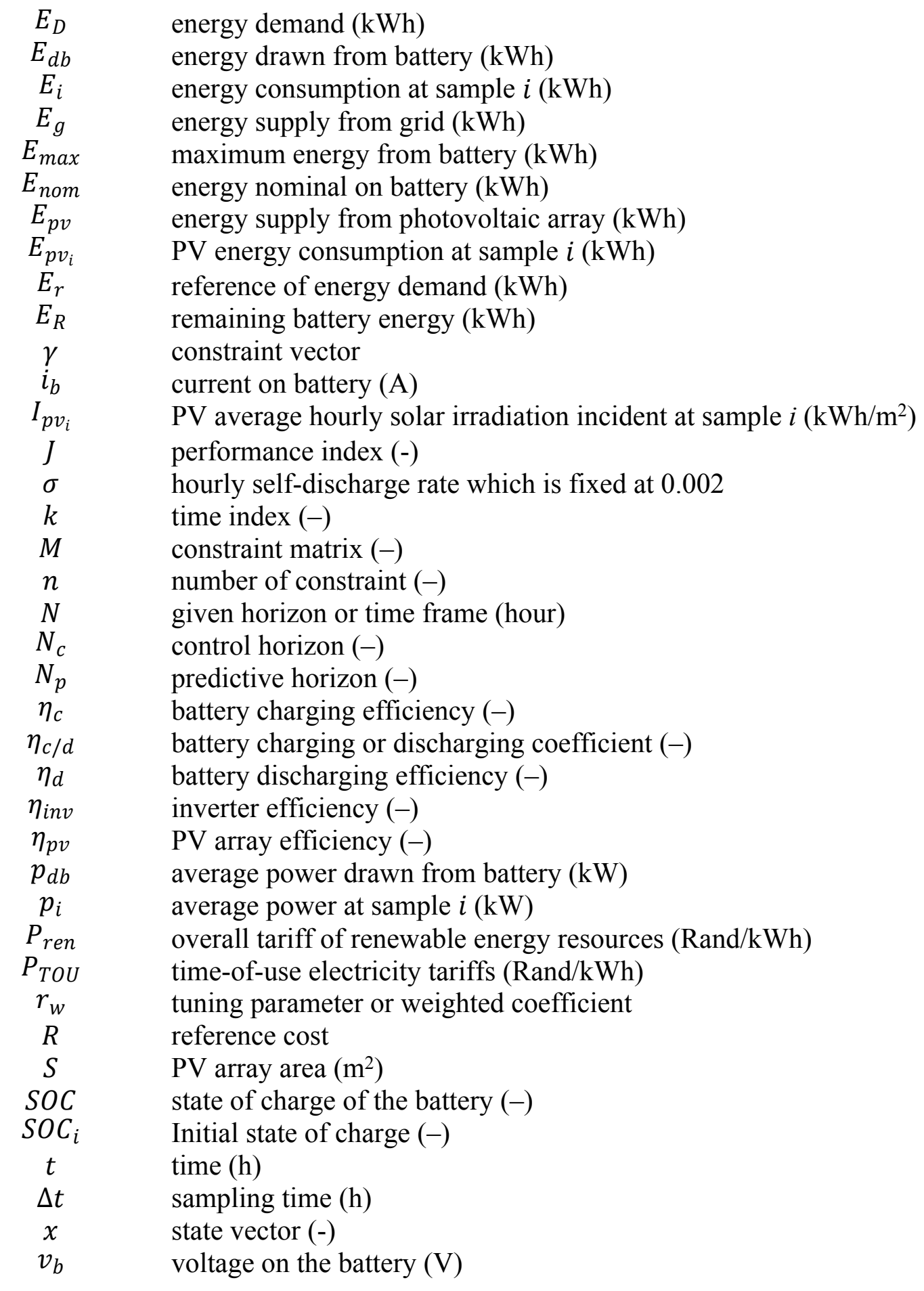

\section{INTRODUCTION}

The deployment of buildings' energy management systems started in the 1970s when the development of direct digital control signal from the advent of a microprocessor was introduced. It offers the ability to control and manage the energy system by providing the users with a betterquality environment. Since its inception, it has been observed that the development of energy 
management systems in buildings minimises the overall energy consumption of the building, which is an advantage to end users despite the technology cost [1]. The technology has since continued to develop to improve the overall performance of the buildings' energy systems as well as improving user satisfaction and experience. Additionally, the recent deployment of smart grid technologies offer overall support for new and advanced energy efficiency services in the electric power system [1], which enhance the network management and contribute to the achieve the high reliability indexes [2]. Thus, the application of smart grid technologies can permit multiple applications of energy saving, operational efficiency improvement and determination of real-time adequacy of supply margins [3]. The smart meter is often considered as the key for smart grid development since it offers several advantages in electrical system information and communication [4]. One of the benefits is to permit the consumers to participate proactively in electricity energy markets [5-7].

Six major approaches to manage the energy demand of a given building are described in the literature: peak clipping, valley filling, load shifting, strategic conservation, strategic load growth, and flexible load shape [8]. These load management methods have the potential to reduce the overall cost of energy in a system. Thus, demand optimisation entails modeling approaches of the system behaviour, which can be designed according to each of the above mentioned methods. Valley-filling and load-shifting strategies are both useful approaches that can be implemented for some defined kinds of loads, but they are less effective in commercial buildings applications due to the specified time of the highest daily energy demand. On the other hand, peak clipping is the most effective method for commercial buildings applications $[6,7]$ because the daily peak of the energy demand in a commercial building is mostly from late-morning to early-evening. It is also important to note that flexible load shape strategy could also give the same performance as peak clipping. The main objective of all demand-side management approaches is to induce a dynamic behaviour on electrical loads, which creates a flexibility on the power system that can reduce the cost of energy consumption $[9,10]$.

The development of the dynamic approach of energy management permits the flexibility and the efficiency of the energy cost optimisation. Several strategies develop the algorithm that can improve the energy management of the electrical system and optimise the cost of electricity consumption [11-13]. In this manner a specific mathematic concept creates a dynamic system strategy [12]. Further, the real-time electricity pricing method allows the dynamic strategy of the energy cost optimisation on the electrical system [13]. It is important to notice when the electricity usage, the time of day and the energy demand are established, the electricity pricing 
dynamic can be developed, and it can be considered as a real-time electricity pricing environment [4-7]. This method can improve the efficiency of the power grid, reduce the peak demand, and mitigate the instability of electricity price. In general, real-time electricity pricing is a function of the customer location, weight of consumption, and the type of load $[6,7]$. Therefore, it can be considered as a time variant function [6] or not [7], and it can be set by both the utility and the consumer for more flexibility of the energy cost [10]. MPC-based energy management system is considered as one of the accurate strategies that can effectively ensure control of the electrical system and reduce the overall cost of energy in real-time in many works.

However, there are not many studies optimizing energy costs based on the real-time pricing with TOU, renewable energy tariffs and consumer's flexibility. To coordinate such an adaptive system, a specified energy demand target from the utility grid is required $[6,7]$. This study is trying to close the gap of adapting different electricity pricing schemes in real-time environment through a smart metering system. As an advanced model [7], this paper introduces an optimal strategy of energy flow coordination and consumption cost reduction using an adaptive TOUMPC managing system. The renewable energy is integrated by controlling the PV solar and battery energy storage system (BESS) using adaptive TOU-MPC managing configuration. Two demand seasons (Southern Hemisphere) of the year in South Africa are considered for performance evaluation. The daily energy demand and the reference of energy consumption for the low period (L-P) "summer" and high period (H-P) "winter" of commercial energy demand applications in the city of Tshwane are used to investigate the performance of the system design.

The main contribution of this paper is the introduction of an adaptive energy flow coordination, based on real-time pricing environment, into all levels of utility's TOU electricity tariffs combined with renewable energy tariffs. This structure is designed through MPC-based energy management system to minimize the energy cost consumption from the utility grid for a commercial building. A discrete dynamic model of the principal components of energy costs on the system, i.e. grid energy cost, renewable energy cost and total energy cost of the consumer, is augmented with the dynamics of BESS to fashion the system structure in MPC framework. The smart metering system, where two-way communication is available $[3,10,14]$, can be used to share the information with the MPC controller in real-time.

The remainder of the paper is organised as follows. Section 2 conducts and discusses a comprehensive literature review. Section 3 describes the system background and component for an optimal electrical cost reduction of a commercial building. The proposed design strategy with 
MPC is presented in section 4. Section 5 presents the results achieved, as well as their analysis. The paper is concluded in section 6 .

\section{LITERATURE REVIEW}

Real-time electricity pricing using energy management system, in the literature, refers to systems which are designed to optimise the energy flow and the cost of energy consumption. The principal aspects that are offered by such systems have been analysed in an extensive literature review of real-time pricing, which highlights benefits, opportunities, costs, and risks of real-time pricing strategies [15]. It is observed that the implementation of real-time electricity pricing brings several advantages for the electrical system. In this study, MPC-based energy management system is used to design the dynamic behaviour for the energy flow coordination, which optimises the cost of energy consumption for a commercial building in a real-time pricing environment. The use of MPC algorithms to reduce the cost of energy consumption has been studied on diverse published works. Several works focused on energy management of specified appliances or standalone energy supply system that can be injected into the electrical system.

\subsection{Real-time electricity pricing approach}

The real-time computation is used as part of smart grid technology to enhance the overall performance of an electric power system [ 14-16]. In [16], a dynamic load management for a residential customer using reinforcement learning approach is addressed to find an optimal solution that can substantially increase the efficiency of the energy system and reduce the energy bills and the peak load. The paper presents a smart energy hub which is supported by real-time computing that monitors and control the energy usages. In [17], real-time electricity pricing is combined with a stochastic model of natural-gas prices and electricity demands to build up an accurate framework for smart energy hubs. This system can reduce the operational cost in an uncertain environment. In [18], a demand side management approach using smart grid technology is proposed as a model that would enable user side load control strategy. Additionally, demand side management can use a passive controller that can efficiently react to real-time pricing. Moreover, real-time pricing could create an effective balance between the demand and the supply. A hybrid algorithm called genetic binary particle swarm optimization is presented as a new heuristically optimised home energy management controller strategy for smart grid in [19]. The proposed approach is implemented in real time electricity pricing 
environment and the system reduces the electricity bills and curtail the peak-to-average power ratio.

Wang et al. [20] have presented how the implementation of real-time electricity pricing can optimise the overall energy consumption for a residential user. It is also observed that a dynamic pricing approach based on real-time policy can optimally shift the electricity demand from peak period to off-peak period. This strategy leads to the optimal reduction of the overall cost of the system operation [21]. In [22], the performance and feasibility of electricity pricedbased control models is analyzed for thermal storages in households. The paper estimates the influence of different models and volatility of the real-time pricing on the energy cost and electricity consumption, taking into account the comfort levels inside the building. The proposed strategy ensures a maximal electricity saving. In [23], a day-ahead real-time pricing tariff is presented as dynamic pricing strategy to build up a Dijkstra's algorithm that deals with the operation scheduling of electric water heaters. Through a given preference of the user, the objective function aims to optimise the energy cost and the user's comfort. Thus, the electrical water heaters can operate as a smart system that minimise the cost of energy consumption.

\subsection{MPC-based energy management}

The investigation on different aspects of energy cost optimisation using MPC to coordinate the energy management for an electrical system has been conducted during recent years. In [24], an MPC system is designed for a commercial building to optimally manage in real time the energy supply from the grid, PV, and energy storage system. This strategy reduces cost and achieves load rump-rate reduction from the grid. In [25], the building energy management system under demand response program using an MPC is proposed to reduce the energy cost. This work introduces the new concepts of integrating the volume of price signals into the system regulation of the temperature and develops the strategy of cost-optimal control for large-scale buildings. A modified stochastic MPC method is established for the energy coordination procedure of a plugin hybrid electric bus in [26]. The designed model considers the unknown driver inputs in the prediction horizon as the stochastic disturbance data. This method is appropriate for the city bus driving conditions and can be converted to the online control strategy. In [27], central and standalone MPC is proposed to challenge different electricity pricing schemes as a market behaviour for residential buildings. The designed system aims to minimise the operation cost under a real-time five minutes pricing. It is observed that this method can achieve from 20 to 30 $\%$ cost saving of a specific appliance, and overall of $42 \%$ for all system. 
In [28], a new adaptive control strategy is investigated for a dynamic approach of the building energy efficiency. This approach controls and optimises the energy consumption through a model reference adaptive control to guarantee the indoor comfort of a building. In [29], a MPC is presented as an optimal control strategy that can efficiently save the energy consumption and achieve the required building comfort levels. In [30], an optimisation strategy for a hybrid PV-wind-battery system using an MPC was designed. The scheme coordinates the energy flow for a business building in a smart grid environment to optimally reduce the energy consumption from the grid and maximise the use of renewables. An integrated power management system for plug-in hybrid electric vehicles and an assistance power unit is presented in [31]. This research designs a control strategy that integrates the MPC controller to promote economic savings. In [32], a robust and economical closed-loop MPC approach that can handle the energy flow of a hybrid system is investigated. This strategy shows that the MPC is robust and reliable to deal with the overall system disturbances.

A modular coordination of building comfort and microgrid energy flows using an MPC scheme is presented [33]. The developed smart building scheme enables cost savings under microgrid energy price profiles. In [34], an event driven MPC strategy for an energy management system of residential electricity prosumers is designed in the context of near real time load shifting control. This approach aims to enable the consumers to actively participate in demand side management programs by managing self-consumption while reducing the cost of energy. In [35], an MPC approach is used to develop an operation management system that can reduce energy consumption in residential buildings. This strategy contributes with three novel concepts, which consist of coordinating forecasting, operational planning, and operation control. A realtime energy management approach for optimal renewable generation management, using an MPC for a microgrid, is presented in [36]. This strategy reduces the overall cost of the mcirogrid and improves the operation of a hydrogen energy storage. In [37], a new modeling approach is introduced to coordinate an energy storage system, renewable energy generation and energy prices using a MPC. This system allows the optimal integration of renewable energy on the electrical system.

The integration of renewable energy in a real-time electricity-pricing environment using an MPC to reduce the cost of power consumption for a commercial building is recommended in $[6,7]$. In the smart city and microgrid development context, it is observed that the integration of a solar energy generating system to the grid is environmental friendly for any commercial load [38]. When the renewable energy is combined with the energy storage system can efficiently 
ensure the continuity of the optimal power supply [38, 39]. Several approaches have been implemented to manage the energy demand by optimising the consumer cost of electricity. The use of a MPC is encouraged in the energy management system [8-9] and recommended for a time-variant system to reduce the overall cost of electricity $[39,40]$. However, several gaps are found in a time-variant electricity pricing system, which consists of TOU electricity tariffs and the introduction of renewable energy tariffs in the real-time environment.

This paper investigates an adaptive MPC managing system that can deal with the dynamic behaviour of the energy flows on the electrical system. The study also presents a real time electricity pricing structure, which designs a discrete state space model of the energy cost. This is combined with the dynamic model of the energy storage system for the robustness of the schematic layout of the MPC design.

In this study, a novel real-time pricing approach and adaptive based MPC is introduced for energy cost optimisation of a commercial building. The control design considers an objective function with constraints that could follow any given consumer's target. To achieve this performance, we pursue the following goals: first considering real-time pricing, a model is developed for discrete energy cost optimisation with specific tariff schemes; then an adaptive strategy is designed in the framework of smart grids to include MPC and a real-time electricity pricing environment. In addition, an approach to optimally manage PV-BESS in the context of a real-time electricity pricing structure for commercial buildings is also developed. The overall designed approach gives consumers the opportunity to deal with the cost of electricity usage and to play an active role into the amount of energy consumed and allow the utility to ensure an optimal energy supply. Therefore, the novelty of this paper is the strategy and modeling of the adaptive technique based on MPC for energy management in commercial buildings in a holistic and systematic perspective to optimize energy costs. This model combines various energy pricing schemes in a discrete real-time energy cost approach.

\section{SYSTEM METHODOLOGY}

\subsection{System Hypothesis}

This research provides the optimal strategy of energy reduction according to the purpose given by the interior system design by prioritising some of the loads on the demand side. This strategy allows the consumers to define the reference or the target energy that they are willing to pay to the utility grid. The energy tariff values are divided by the range of prices, which are fixed for every day of the specific season. The integration of renewable energy resources is optimal. Page 9 of 38 
In case of excessive energy from PV and battery storage, the surplus of energy can be injected into the grid without any compensation. It is allowed self-consumption on the system, which means that renewable energy price is evaluated as an opportunity cost. The opportunity cost is the best available alternative. This means that the energy from the battery or PV is more valuable when the cost on the utility side is higher. It is important to notice that the converter efficiency of PV and battery storage are the same. Therefore, the designed approach could efficiently operate in the smart grid environment.

\subsection{Real-time electricity pricing and demand management}

The electricity cost is established in $[6,7]$ as the function of the energy demand and the real-time price of electricity. The utility sets the price of electricity, and through a smart meter communication, the consumer can track it in real-time. The real-time electricity cost is expressed as a function of TOU scheme as follows [9]:

$$
c(t)=\int_{0}^{N} P_{T O U} E(t) d t
$$

where $c$ is the cost of electricity to pay [Rand], $E(t)$ is the instantaneous energy consumption [kWh], $N$ is a given horizon or time frame [hour], and $P_{T O U}$ is the TOU-Tariffs [Rand $/ \mathrm{kWh}$ ]. The TOU electricity tariff of the utility grid in South Africa (City of Tshwane) for commercial usage during low and high demand period is presented in Table 1 [41]. TOU is divided into three parts of the day that start from $00 \mathrm{~h} 00$ to $24 \mathrm{~h} 00$. These are an off-peak period from $00 \mathrm{~h} 00$ to $7 \mathrm{~h} 00$ and from $21 \mathrm{~h} 00$ to $24 \mathrm{~h} 00$, the standard time from $7 \mathrm{~h} 00$ to $8 \mathrm{~h} 00$ and from $11 \mathrm{~h} 00$ to $18 \mathrm{~h} 00$, and peak period from $8 \mathrm{~h} 00$ to $11 \mathrm{~h} 00$ and $18 \mathrm{~h} 00$ to $21 \mathrm{~h} 00$.

The energy flow on the system depends on the active power and it can be expressed as follows;

$$
E_{i}(k)=\Delta t \sum_{k=1}^{N} p_{i}(k)
$$

where $\Delta t$ is the sampling time, and $p_{i}$ is the average power at sample $i$. 
Table 1. Daily Load Profiles and TOU Electricity tariffs

\begin{tabular}{|c|c|c|c|c|c|c|c|c|c|c|c|c|c|}
\hline \multirow{2}{*}{$\begin{array}{c}\text { Time of } \\
\text { day }\end{array}$} & \multicolumn{3}{|c|}{ Low demande period (L-P) } & \multicolumn{3}{|c|}{ High demande period (H-P) } & \multirow{2}{*}{$\begin{array}{c}\text { Time of } \\
\text { day }\end{array}$} & \multicolumn{3}{|c|}{ Low demande period (L-P) } & \multicolumn{3}{|c|}{ High demande period (H-P) } \\
\hline & Load & Target & TOU tariff & Load & Target & TOU tariff & & Load & Target & TOU tariff & Load & Target & TOU tariff \\
\hline hour & $\mathrm{kWh}$ & $\mathrm{kWh}$ & Rand & $\mathrm{kWh}$ & $\mathrm{kWh}$ & Rand & hour & $\mathrm{kWh}$ & $\mathrm{kWh}$ & Rand & $\mathrm{kWh}$ & $\mathrm{kWh}$ & Rand \\
\hline 00:00 & 15 & 15 & 0,5125 & 15 & 15 & 0,615 & 12:00 & 70 & 30 & 0,725 & 80 & 30 & 1, 1,073 \\
\hline 01:00 & 15 & 15 & 0,5125 & 20 & 20 & 0,615 & 13:00 & 70 & 30 & 0,725 & 80 & 30 & 1,073 \\
\hline 02:00 & 15 & 15 & 0,5125 & 20 & 20 & 0,615 & 14:00 & 70 & 30 & 0,725 & 80 & 30 & 1,073 \\
\hline 03:00 & 15 & 15 & 0,5125 & 20 & 20 & 0,615 & 15:00 & 70 & 30 & 0,725 & 80 & 30 & 1,073 \\
\hline 04:00 & 15 & 15 & 0,5125 & 20 & 20 & 0,615 & $16: 00$ & 50 & 30 & 0,725 & 60 & 30 & 1,073 \\
\hline 05:00 & 15 & 15 & 0,5125 & 20 & 20 & 0,615 & $17: 00$ & 50 & 30 & 0,725 & 60 & 30 & 1,073 \\
\hline 06:00 & 15 & 15 & 0,725 & 20 & 20 & 1,073 & 18:00 & 50 & 20 & 1,1514 & 60 & 30 & 4,115 \\
\hline 07:00 & 15 & 15 & 1,1514 & 20 & 20 & 4,115 & 19:00 & 50 & 20 & 1,1514 & 60 & 30 & 4,115 \\
\hline 08:00 & 70 & 30 & 1,1514 & 80 & 30 & 4,115 & 20:00 & 50 & 20 & 1,1514 & 60 & 30 & 4,115 \\
\hline 09:00 & 70 & 30 & 1,1514 & 80 & 30 & 4,115 & 21:00 & 15 & 15 & 0,5152 & 20 & 20 & 0,615 \\
\hline 10:00 & 70 & 30 & 0,725 & 80 & 30 & 1,073 & 22:00 & 15 & 15 & 0,5152 & 20 & 20 & 0,615 \\
\hline 11:00 & 70 & 30 & 0,725 & 80 & 30 & 1,073 & 23:00 & 15 & 15 & 0,5152 & 20 & 20 & 0,615 \\
\hline
\end{tabular}

\subsection{Solar Energy resource}

South Africa, with its abundant sunshine, is placed in the top 3 solar energy resource areas in the world. This ranking is due to its annual average sunshine rate of more than 2500 hours with an average range of direct solar radiation intensities of between 4.5 and $6.5 \mathrm{kWh} / \mathrm{m}^{2}$ per day [42]. Solar generation is a function of the type of array used in solar panel devices, as described in $[38,43]$. Thus, South Africa's solar generation can reach more than $8 \mathrm{kWh} / \mathrm{m}^{2}$ per day. This depends on location and station identification as well as the PV system specifications. The power rating or the energy conversion from solar is also a function of the electrical parameters, solar spectrum, temperature, the optical properties of the array and the amount and direction of incident radiation [38].

\subsubsection{Energy Rating of PV array}

The daily energy generation by the photovoltaic array is described by Eq. (3). This equation derives from the hours rating power of photovoltaic panel per unit of a surface [38], and it is formulated by using Eq. (2). It is also dependent on the efficiency of the solar cell.

$$
E_{p v_{i}}(k)=\Delta t \eta_{p v_{i}} S \sum_{k=1}^{N} I_{p v_{i}}(k)
$$

where $S$ is the total PV array area, $\eta_{p v}$ is the efficiency of the PV array, $I_{p v_{i}}$ is the hourly solar irradiation incident on the PV array, and $E_{p v}$ is the hourly energy of the PV generator. It is worth noting that the rating power of a PV array depends on geometric conditions and the atmospheric conditions (i.e. sun temperature) [44].

Figures 1(a)-(b) depict the plane of array irradiance of a low demand period (L-P) and high demand (H-P) of the City of Tshwane in specified days [43]. These show the several of daily 
measured plane of array irradiance of different solar PV technology in South Africa. It is therefore important to notice that for an optimum design of a PV system the lowest specified day should be chosen for L-P and H-P. The selection depends on the lowest daily peak of the plane of array irradiance for fixed open crack PV technology, and the lowest monthly average of solar irradiance during the L-P and H-P respectively. Please notice in Fig. 1.b, the influence of shad (possibly cloud affecting the theoretical cure of irradiance, as seen by the array).

\subsection{Energy storage system}

Two possibilities of energy storage technologies can be defined. On one hand, it consists of maintaining the quality of voltage supply which is based on the stability of the high cycle, and the rating output power supplied at short duration. On the other hand, it involves shifting the time which is based on the long-term storage, and the need for fewer cycles [45]. 


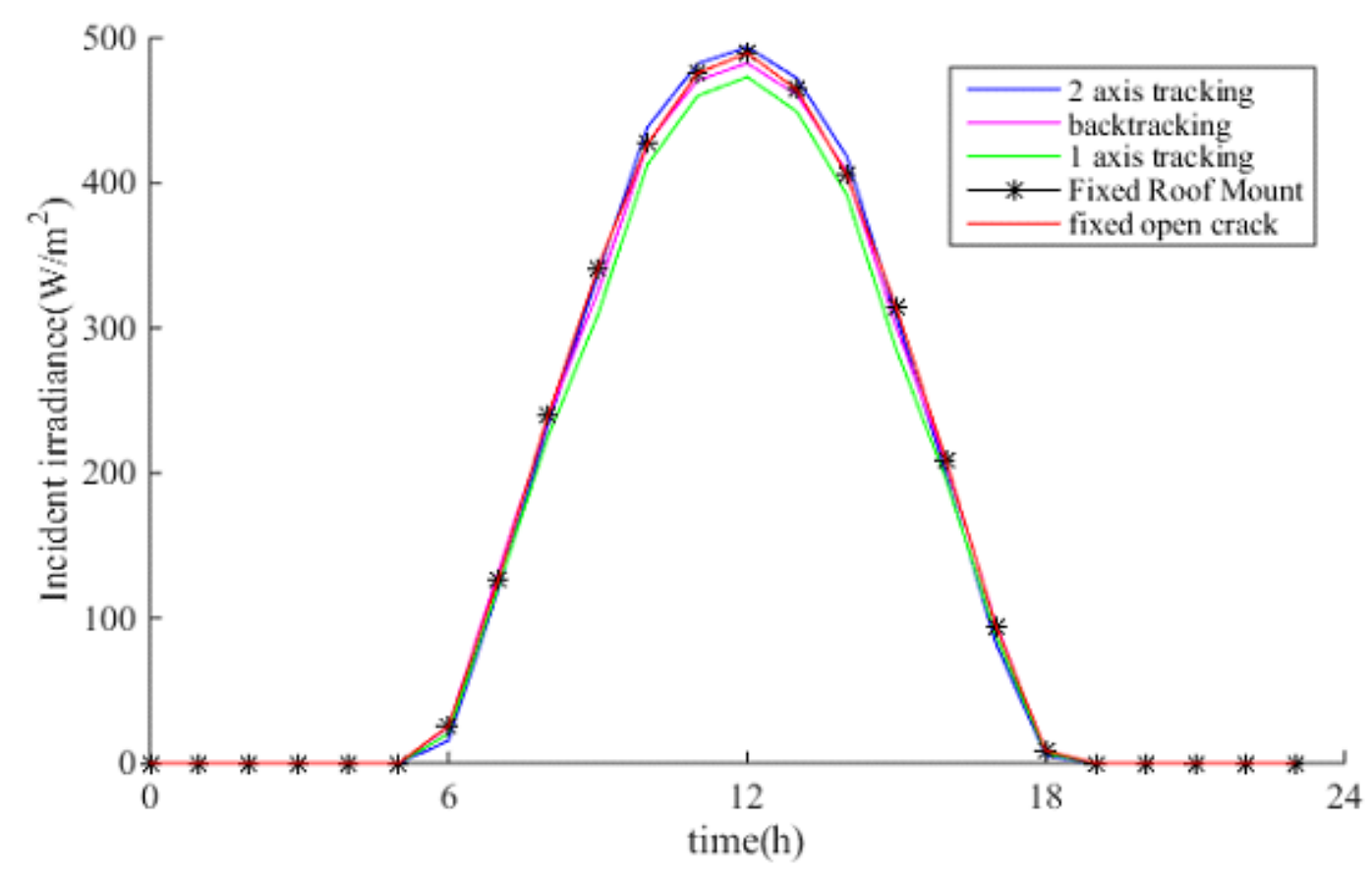

(a) Low demand season $\left(17^{\text {th }}\right.$ February 2016$)$

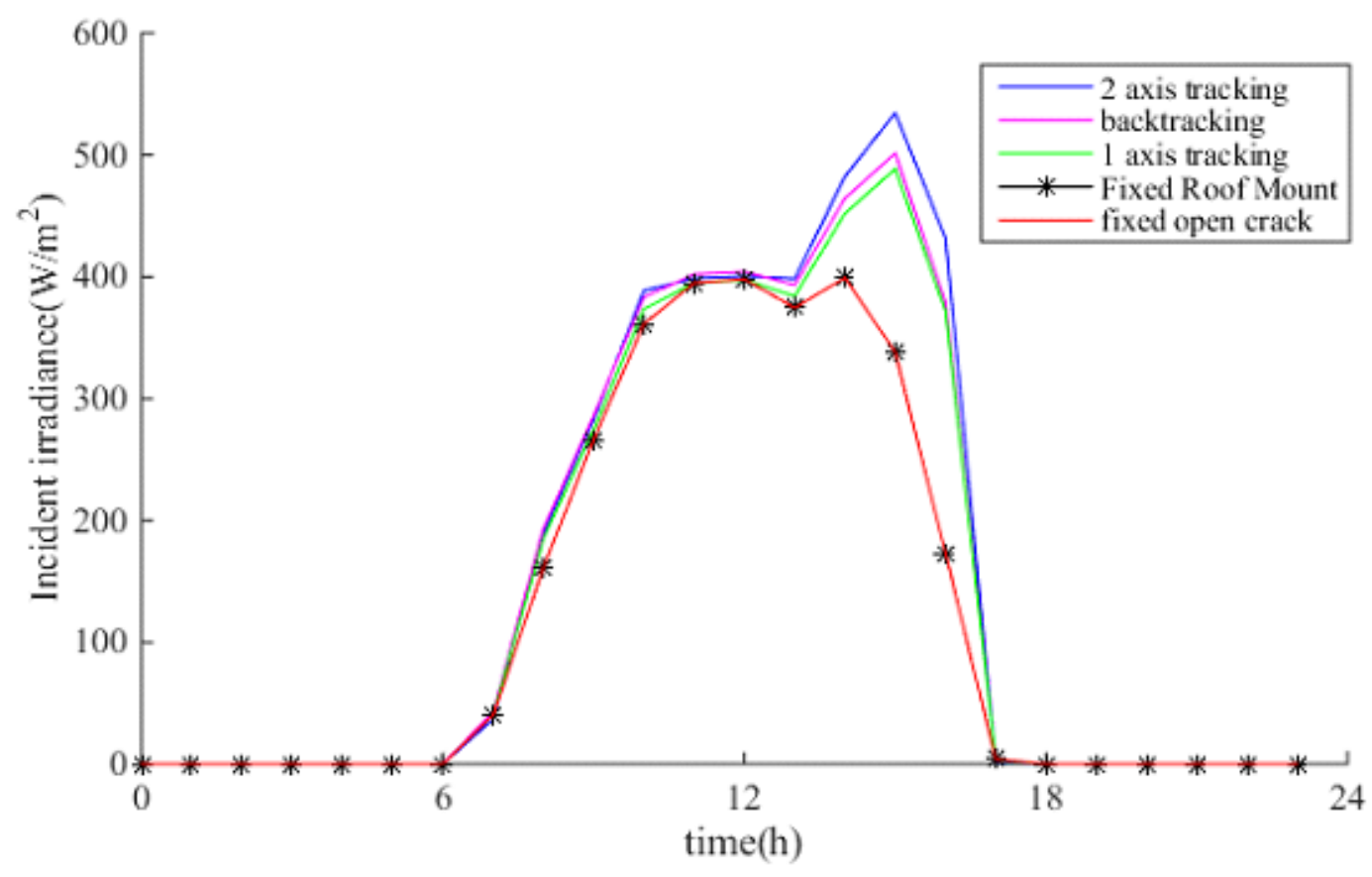

(b) High demand season (12 $2^{\text {th }}$ June 2016)

Fig. 1. Daily plane of array irradiance [43].

\subsubsection{Battery energy storage system}

BESS, as well as other storage systems, are mainly chosen by considering the storage characteristics and parameters including the available energy, autonomy, costs, depth of 
discharge or power transmission rate, discharge time, durability (cycling capacity), efficiency, feasibility and adaptation to the generating source, mass and volume densities of energy, selfdischarge, and storage capacity. Moreover, environmental aspects, monitoring and/or control equipment, operational constraints, reliability, and other technical characteristics describe the easy way to maintain the system. This is based on the simplicity of the design, operational flexibility, and the capacity to release the stored energy [46]. Therefore, BESS offers a long-term integration of energy storage for renewable energy systems. This can be a fixed or a mobile box as per the application [47]. In a power system, a right approach to choosing a battery is to base it on its performance characteristics such as cycle and calendar lifetimes; operational and maintenance requirements; power rating and energy storage capacity; round-trip energy efficiency levels; safety and licensing considerations; size; and whole life cost [48].

\subsubsection{Dynamic model of battery}

The energy storage market has many manufacturers and different kinds of battery storage systems. The PV module mostly uses batteries that generate energy in the form of chemical energy storage. It is important to note that chemical energy storage has a chemical component as a main element of the device. However, electrochemical energy storage, as part of chemical energy storage, has fuel cells as the principal component of the device or battery.

The renewable energy resources (wind and solar) are designed in combination with the batteries storage systems to overcome the fluctuations in the state of the wind and solar. These are devised with two chief objectives: First, to store the energy (charging process) when the resources are more than setting demand, and then the same stored energy is used to supply the load where the demand increases, or the resources decrease (discharging process). Equation (4) expresses the generated energy by the BESS $[49,50]$ that describes the process of charging and discharging. This manner represents the state of charge of the battery.

$S O C=\frac{E_{R}}{E_{\max }}$

where $S O C, E_{R}$ and $E_{\max }$ are the state of charge of the battery, the remaining battery energy, and the maximum energy from battery respectively. With $E_{R}=E_{\max }-E_{d b}$, and $E_{d b}$ is the energy drawn from battery which is described as:

$E_{d b}=\int v_{b} i_{b} d t$ 
By combining Eqs. (4) and (5) and the developed state of charge model in [51], the dynamic model of the state of charge in continuous time of function of charge and discharge of the battery can be described as follows:

$\operatorname{SOC}(t)=\operatorname{SOC}_{i} \pm \frac{1}{E_{\text {nom }} \eta_{c / d}} \int_{0}^{t} p_{d b} d t$

where $t, S O C_{i}, E_{n o m}, \eta_{c / d}$, and $p_{d b}$ are respectively, the instant time in which the battery dynamic is considered, the initial state of charge of battery, the nominal energy of the battery, the battery charging or discharging coefficient, and the power flowing from the battery which can be negative in charging state and positive in discharging state. It is also important to notice that $\eta_{c / d}=1 / \eta_{c}$ or $\eta_{c / d}=\eta_{d}$ with $\eta_{c}$, and $\eta_{d}$ are battery charging and discharging efficiency respectively. The dynamic functions of the energy flow on the battery system during each operating state are functions of (7) and (8) [52].

$$
\begin{aligned}
& E_{c}(t+1)=E_{c}(t)(1-\sigma)+\left(E_{p v}-E_{D}(t) / \eta_{i n v}\right) \eta_{c} \\
& E_{d}(t+1)=E_{d}(t)(1-\sigma)-\left(E_{D}(t) / \eta_{i n v}-E_{p v}(t)\right) / \eta_{d}
\end{aligned}
$$

where $E_{c}, E_{d}, E_{D}, \sigma, \eta_{i n v}$ are respectively, charging energy, discharging energy, energy demand, hourly self-discharge rate which is fixed at 0.002 , and the efficiency of the inverter.

\section{SYSTEM MODELLING AND DESIGN}

\subsection{System description}

The structure of the optimal system that is described in Fig. 2 is devised in the core of an energy management system. In practical deployment, the proposed MPC-based energy management model has the potential to minimise the consumer's energy demand in real-time. The proposed strategy presents an adaptive control where the flow of energy is specified to describe the system design as established in Fig. 2. Figure 2 describes the adaptive model of the advanced model in real-time electricity pricing. In this tariff scheme, the system is automatically updated in response to real time changes in electricity prices; which entails adaptation of the device to the control variable (the energy flow) according to the TOU electricity tariff. It is shown in Fig. 2, that the set system constitutes four inputs and four outputs. K1 and K2 are the smart 
switches which follow a control signal from the MPC managing system. The controller of the energy storage system, K2, can be either in charging or discharging state. Thus, the proposed system is designed with multiple input and output signals to emulate a MPC scheme where the state space is considered as the principal parameters of the system. The system is automatically updated following the real-time variation of the electricity pricing. It consists of adapting the mechanism to the control variable (the energy flow) according to the TOU electricity tariff. This strategy consists of combing each TOU range on its MPC controller i.e. off peak MPC, standard MPC and peak MPC.

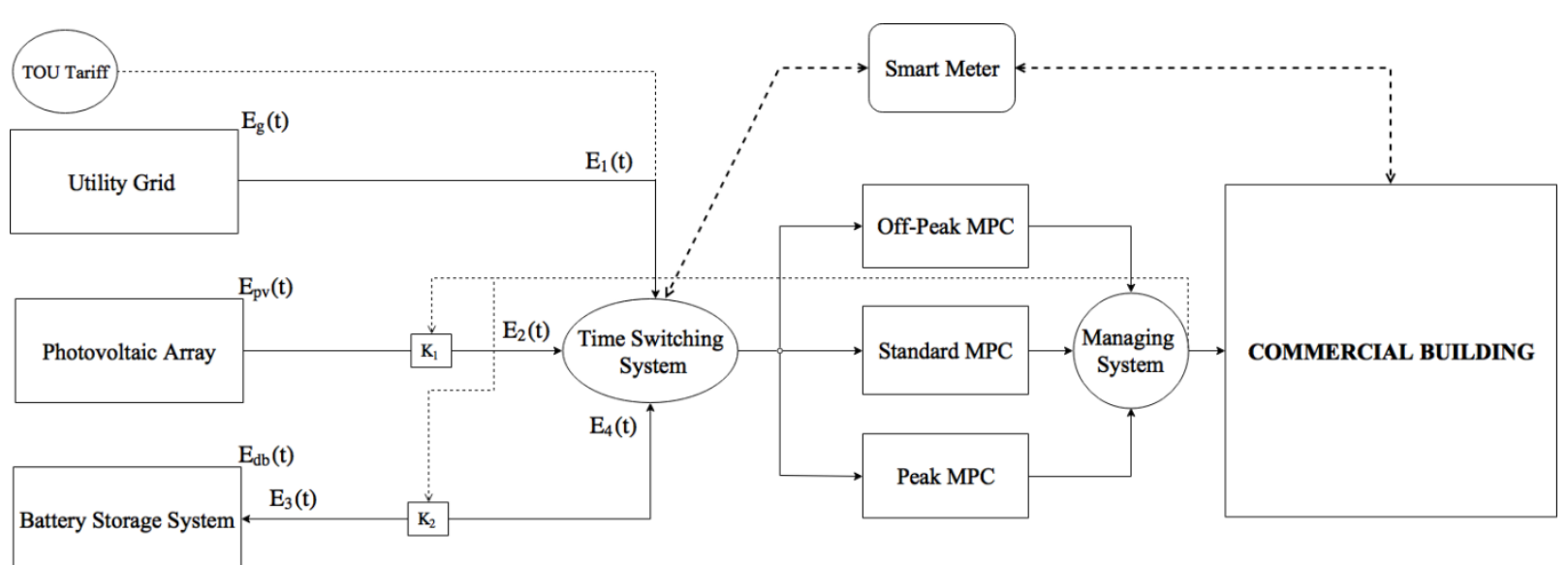

Fig. 2. Adaptive TOU-MPC managing system.

The energy flowing through the battery side depends totally on the power generated from the solar PV array. The battery storage system has a bi-directional energy flow system as described by Eqs. (7) - (8) and Fig. 2. Equation (3) describes the energy flow in the solar PV array, which is a function of solar irradiation as depicted in Fig. 1(a)-(b). The developed system of the basic model [8-9] focus on the optimisation of the energy demand from the utility grid. This energy management approach is accurate and optimal in managing the supply side of the system when integrated with the MPC. for the advanced model described in Fig.2, the energy generated from the utility grid cannot charge the battery storage system (BSS). Through the model proposed in Fig. 2, Eqs. (9) - (12) establish the energy flow on the system as follows:

$$
\begin{aligned}
& E_{g}(t)=E_{1}(t) \leq E_{r}(t) \\
& E_{p v}(t)=E_{2}(t)+E_{3}(t) \\
& E_{d b}(t)=E_{3}(t) \text { if } E_{d b}(t) \leq 0 \\
& E_{d b}(t)=E_{4}(t) \text { if } E_{d b}(t) \geq 0
\end{aligned}
$$


where $E_{g}(t)$ is the energy supply from grid, $E_{p v}(t)$ is the energy flow from solar PV array, $E_{r}(t)$ is the reference energy demand, and $E_{d b}(t)$ is the energy generated by battery storage. Whereas $E_{i}(t)$, with $i=1,2,3$ and 4, are the energy flow of the utility grid, the solar PV, and the battery charging and discharging energy respectively. From Eq. (7) to (12), it is seen that the energy flows in Fig. 2 expressed as follows:

$E_{D}(t)=E_{1}(t)+E_{2}(t)+E_{4}(t)$

where $E_{D}(t)$ is the load demand which depends on the energy supplies from the grid, PV and discharging of the battery. The battery charging, and discharge energy described by Eqs. (7) and (8) can be rewritten as a function of the energy flows on the PV and on demand side as follows:

$E_{3}(t)=E_{2}(t)-\frac{E_{D}(t)}{\eta_{i n v}}$

$E_{4}(t)=\frac{E_{D}(t)}{\eta_{\text {inv }}}-E_{2}(t)$

\subsection{System design}

An MPC system design is developed in state-space or transfer function model, and it can be either in continuous or in discrete time [53]. However, in digital control system design, the discrete time models are widely used because of its high-performance. Through this strategy, the discrete-time system model equations described in [6,7], which is a standard model in digital control systems, is developed. The advanced adaptive MPC system management developed in Fig. 2 can be rewritten in continuous state space model as

$\left\{\begin{array}{l}\dot{x}(t)=A x(t)+B E(t) \\ c(t)=C x(t)+D E(t)\end{array}\right.$

where $A, B, C$ and $D$ are respectively, the state matrix, input matrix, output matrix, and feed forward matrix respectively. $x, c$ and $E$ are state vector, output vector and control or input vector respectively. For $t \geq 0, x(t) \in \mathbb{R}^{n}, c(t) \in \mathbb{R}^{q}$, and $E(t) \in \mathbb{R}^{p}$ these involve that $\operatorname{dim}[A]=n \times n$, $\operatorname{dim}[B]=n \times p, \operatorname{dim}[C]=q \times n$ and $\operatorname{dim}[D]=q \times p$. Due to the absence of direct feed through on the system model developed in [7], it is assumed that the feed forward matrix of the advanced adapted model is also zero.

From Eq. (1), the continuous state space model is developed for a single input and single output system as described in [6,7] (basic model). From Fig. 2, and Eqs. (9), (10) and (13), the cost of Page 17 of $\mathbf{3 8}$ 
energy flow on the system in real-time can be defined. This structure is discretised using Euler's forward approximation method described by $[6,7]$, and it can be rewritten as follows:

$c_{1}(k+1)=c_{1}(k)+P_{\text {TOU }} E_{1}(k)$

$c_{2}(k+1)=c_{2}(k)+P_{r e n}\left(E_{2}(k)+P_{3}(k)\right)$

$c_{3}(k+1)=c_{3}(k)+P_{\text {TOU }} E_{1}(k)+P_{r e n}\left(E_{2}(k)+E_{4}(k)\right)$

where $c_{1}, c_{2}$ and $c_{3}$ are respectively, the grid energy cost, the renewable energy cost, and the total energy cost of the end consumer. $k=T t$, with $T$ as a given period of the system, and $k$ is the sample of time and $k \in \mathbb{Z}^{T}, P_{\text {ren }}$ is the overall tariff of renewable energy resources that includes the operation and the maintenance cost of PV and battery storage. Equation (20) is the discrete formulation of the state of charge of the battery storage developed using the Euler forwarding method. It is derived from Eqs. (5) and (6). Equation (21) is the generic formulation of the energy storage developed from the dynamic models of the energy storage system Eqs. (6) and (8).

$\operatorname{SOC}(k+1)=\operatorname{SOC}(k) \pm \frac{E_{d b}(k)}{E_{n o m} \eta_{c / d}}$

$E_{c / d}=E_{c / d}(k)(1-\sigma)+E_{3}(k) \eta_{c}-E_{4}(k) / \eta_{d}$

From Eqs. (17) to (21), the system modelling is described in discrete state space model. Equation (22) defines the digitalization of the continuous state space model given by Eq. (16) as follows:

$\left\{\begin{array}{l}x(k+1)=A_{d} x(k)+B_{d} E(k) \\ c(k)=C_{d} x(k)\end{array}\right.$

where $A_{d}, B_{d}$, and $C_{d}$ are respectively, the discrete system matrix, input matrix, and output matrix. From Fig. 2 and Eqs. (17) - (22), the input vector of the MPC-based energy management system is described by equation (23).

$E(k)=\left[E_{1}(k) E_{2}(k) E_{3}(k) E_{4}(k)\right]^{T}$ 
The system design entails formulation of all matrices of equation (22) with the energy management system described in Figure. 2. This system is based on real-time energy cost optimization. The system input vector has four elements as expressed in equation (23); therefore, the number of the state vectors has to be equal or more than the dimension of the manipulated variable vector. Equations (17) - (21), therefore, express the state vectors derived from the energy flow of the system Eqs. (9) - (15). By combining the dynamic relations given by Eqs. (17) and (21) with the energies that flow through the system, the system state vector is therefore of dimension 5. It is worth noting that this relationship involves the size of the state matrix of the advanced model. Therefore, the system state vector and matrix can be expressed as follows:

$$
\begin{gathered}
x(k)=\left[c_{1}(k) c_{1}(k) c_{3}(k) \operatorname{SOC}(k) E_{c / d}\right]^{T} \\
A_{d}=\left[\begin{array}{ccccc}
1 & 0 & 0 & 0 & 0 \\
0 & 1 & 0 & 0 & 0 \\
0 & 0 & 1 & 0 & 0 \\
0 & 0 & 0 & 1 & 0 \\
0 & 0 & 0 & 0 & (1+\sigma)
\end{array}\right]
\end{gathered}
$$

By analysing the dimension of Eqs. (23) and (24), the control matrix size is $5 \times 4$. Thus, the input matrix is expressed by analysing the vector Eqs. (9) - (21), (23), (24), (25) and the expressions of discrete state space model given by Eq. (22). Equation (26) is the input matrix. The control matrix is determined as a function of the energy cost as shown in Fig. 2. The state vector is given by Eq. (24) and the state space model expressed by Eq. (16) describe the design approach of the output matrix. One of the research hypotheses set out in this study is that the adoption of the proposed energy management system will reduce the energy cost incurred by the end consumer. Therefore, the energy costs associated with all the energy sources in the system must be accounted i.e. the energy system given by Eqs. (9) - (15), which define the state vectors of the energy costs, and Eqs. (17) - (19) are considered to determine some of the elements of the output matrix. Equation (27) describes the output matrix with the dimension developed from Eqs (23) - (26), which is augmented by the energy flow on the battery Eqs. (7) and (8). Whereas Eq. (28) describes the output vector, and this control variable is derived from the input vector and the state space model as described in Eq. (16). 
$B_{d}=\left[\begin{array}{cccc}P_{T O U} & 0 & 0 & 0 \\ P_{T O U} & P_{\text {ren }} & 0 & P_{r e n} \\ 0 & P_{\text {ren }} & P_{\text {ren }} & 0 \\ 0 & 0 & \frac{\eta_{c}}{E_{\text {nom }}} & \frac{-1}{E_{\text {nom }} \eta_{d}} \\ 0 & 0 & \eta_{c} & -\eta_{d}^{-1}\end{array}\right]$

$C_{d}=\left[\begin{array}{lllll}1 & 0 & 0 & 0 & 0 \\ 0 & 1 & 0 & 0 & 0 \\ 0 & 0 & 1 & 0 & 0 \\ 0 & 0 & 0 & 0 & 1\end{array}\right]$

$c=\left[c_{1} c_{2} c_{3} E_{c / d}\right]^{T}$

where $c_{1}, c_{2}, c_{3}$, and $E_{c / d}$ are respectively, the grid energy cost, the end consumer's total energy cost, the solar PV generation cost, and the energy flow through the battery. By combining the state vector Eq. (24) and the output matrix Eq. (27), the system output cost is only constituted by the grid cost. As the system design should minimise the grid energy cost, it can be assumed that the consumer covers the distributed energy generation (solar PV and BESS) costs.

\subsection{MPC design}

The matrices of state space design given in digital mode that is described from Eq. (24) to Eq. (28) can verify the controllability laws of system design in state space model. The MPC model consists of controlling the optimum approach that the observation sets at each predicted sequence. The performance index of the MPC design is evaluated by the relation (29), which is defined as a quadratic equation $[6,7,53]$.

$J(k)=\left(c(k)-r_{w} R(k)\right)^{T}\left(c(k)-r_{w} R(k)\right)$

Where $c, r_{w}$, and $R$ are the output system or the cost of electricity, the weighted coefficient or the tuning parameter, and the reference cost respectively. After computation of a given a sample $k$ with a given predicted horizon $N_{P}$ and a given control horizon $N_{c}$ through an MPC design, the optimal output or energy cost to pay is defined as follows

$c(k)=F x(k)+\Phi E(k)$ 
where $c(k)=\left[c^{T}(k), c^{T}(k+1 \mid k), \ldots, c^{T}\left(k+N_{P}-1 \mid k\right]^{T}\right.$,

$$
\begin{aligned}
E(k) & =\left[E^{T}(k), E^{T}(k+1 \mid k), \ldots, E^{T}\left(k+N_{P}-1 \mid k\right]^{T},\right. \\
F(k) & =\left[\begin{array}{c}
C_{d} A_{d} \\
C_{d} A_{d}{ }^{T} \\
\vdots \\
C_{d} A_{d}{ }^{N_{p}}
\end{array}\right] \text {, and } \Phi(k)=\left[\begin{array}{cccc}
C_{d} B_{d} & 0 & \cdots & 0 \\
C_{d} A_{d} B_{d} & C_{d} B_{d} & & 0 \\
\vdots & \vdots & \ddots & \vdots \\
C_{d} A_{d}{ }^{N_{P}-1} B_{d} & C_{d} A_{d}{ }^{N_{P}-2} B_{d} & \cdots & C_{d} A_{d}{ }^{N_{P}-N_{c}} B_{d}
\end{array}\right] .
\end{aligned}
$$

By substituting the defined output vector according to the objective function given by Eq. (29), the minimum value of the performance index is, therefore, rewritten as follows.

$$
\min J(k)=\min \left(\frac{1}{2} E(k)^{T} G(k) E(k)+H(k) E(k)\right)
$$

with $G(k)=\Phi(k)^{T} \Phi(k)$, and $H(k)=\left(F x(k)-r_{w} R(k)\right)^{T} \Phi$. Afterwards, optimising the given system by using the MPC design is the effect of implanting a quadratic equation which described Eq. (31) that could be realised whether by a constraining or un-constraining plant model $[7,53]$. Therefore, finding the argument of MV is in relation to minimising the objective function given by Eq. (31).

\subsection{System constraints}

The choice of constraints in the MPC system design is the principal part of the optimal control implementation. The restriction system of an optimal solution in the framework of the MPC model can be set in the function of some important parameters or variables. These parameters are the input signal control and/or its increment, the output signal, and the state vector as well as some equality and inequality constraints $[6,7,53]$. The development of constraints that a given system can have has to be less or equal to the total number of constraints which are defined in the MPC system design. Equation (32) describes the number of constraints that an MPC system design can handle [53].

$$
n=4 m N_{c}+2 q N_{P}
$$

where $m$ is the number of input, $N_{c}$ is the control horizon, $q$ is the number of output, and $N_{p}$ the number of output. For the design system developed from Eq. (24) to Eq. (31), the number of constraints is set as follows:

1. The constraint from a manipulated variable or control signal is imposed by the relation as follows. 
$\left\{\begin{array}{l}M_{1_{j}}=\left[-I_{j}, I_{j}\right]^{T} \\ \gamma_{1_{j}}=\left[-E_{j}^{\min }, E_{j}^{\max }\right]^{T},\end{array}\right.$

where $I_{j}$ is the diagonal identity matrix, $E_{j}^{\min }$ and $E_{j}^{\max }$ are respectively, the minimum and maximum of each $j$ column of control signal as described in Eq. (23) with $j=1,2,3$, and 4 .

2. The knowledge of the system's minimum and maximum input defines the increment of control signal constraint. Thus, the control signal increment is imposed as follows:

$\left\{\begin{array}{l}M_{2_{j}}=\left[-U_{2_{j}}, U_{2_{j}}\right]^{T} \\ \gamma_{2_{j}}=\left[\left(\Delta E_{j}^{\min }+U_{1} \Delta E_{j}\left(k_{i}-1\right),\left(\Delta E_{j}^{\max }-U_{1} \Delta E_{j}\left(k_{i}-1\right)\right]^{T}\right.\right.\end{array}\right.$

where $U_{1}$ and $U_{2}$ are respectively, the identity vector and lower triangular vector in which all elements are one, and $j$ is considered as it is defined in point 1.

3. By Eq. (30), the output constraint is defined as follows:

$$
\left\{\begin{array}{l}
M_{3}=[-\Phi, \Phi]^{T} \\
\gamma_{3}=\left[\left(-c^{\min }+F x\left(k_{i}\right)\right),\left(c^{\max }-F x\left(k_{i}\right)\right)\right]^{T}
\end{array}\right.
$$

where $c^{\text {min }}$ and $c^{\text {max }}$ are respectively, the minimum and maximum cost of electricity to pay to the utility grid.

4. There are two primary constraints of the state vector, which depend on the utility grid and state of charge of battery. Through Eq. (26), the vectors that represent the state constraints can be described as follows:

$$
\begin{aligned}
& \left\{\begin{array}{l}
s v_{1}=\left[\begin{array}{llll}
P_{T O U} & 0 & 0 & 0
\end{array}\right]^{T} \\
s v_{2}=\left[\begin{array}{llll}
0 & 0 & \frac{\eta_{c}}{E_{\text {nom }}} & \frac{-1}{E_{\text {nom }} \eta_{d}}
\end{array}\right]
\end{array}\right. \\
& \left\{\begin{array}{l}
M_{4_{s v_{l}}}=\left[-S S_{s v_{l}}, S S_{s v_{l}}\right]^{T} \\
\gamma_{4_{s v_{l}}}=\left[\left(x_{0_{l}}(k)-x_{l}^{\min }\right) L,\left(x_{l}^{\max }+x_{0_{l}}(k)\right) L\right]^{T}
\end{array}\right.
\end{aligned}
$$


where $S S_{s v_{l}}, x_{0_{l}}, x_{l}^{\min }, x_{l}^{\max }$, and $L$ are respectively, the lower diagonal square matrix of control horizon dimension and $s v_{l}$ element, initial, the minimum and maximum value of state $l$ with $l=1$ and 2 , and identity vector of control horizon row.

5. Equations (23) and (33) demonstrate that it is observed that some additional constraints on the system can be rewritten. These are constituted by the constraint from the utility grid, demand side constraint, restrictions of the PV and battery storage. These additional constraints can be listed as follows:

- Constraints from the utility grid: this is based on the limitation of the energy flow from the utility grid $\left(E_{g}(k)\right)$ as it is described in Fig. 2. The utility grid constraint can be rewritten as follows:

$$
\left\{\begin{array}{l}
M_{5_{1}}=\left[I_{j}^{\prime}\right]^{T} \\
\gamma_{5_{1}}=\left[E_{g}(k)\right]^{T}
\end{array}\right.
$$

where $I_{j}^{\prime}$ is the diagonal identity matrix of the only column with $j=1$, but $j$ has 4 columns as it is described Eq. (33). This means the remaining column has 0 element.

- Solar PV array constraints: the energy flow from the PV array is physically identified as a function of the input signal by the energy flow that supplies the load while charging the battery. Therefore, the PV power is limited to:

$$
\left\{\begin{array}{l}
M_{5_{2}}=\left[I_{j}^{\prime \prime}\right]^{T} \\
\gamma_{5_{2}}=\left[E_{p v}(k)\right]^{T}
\end{array}\right.
$$

where $I_{j}^{\prime \prime}$ is the diagonal identity matrix of two column i.e. $j=2$ and 3 , but the number of columns is described as defined for the utility grid.

- The energy flow on the demand side $\left(E_{D}(k)\right)$ is a function of the different sources; the utility grid, PV and the BESS. Thus, the energy flow on the consumer side is subjected to the following constraint:

$\left\{\begin{array}{c}M_{5_{3}}=\left[N_{j}\right]^{T} \\ \gamma_{5_{3}}=\left[E_{D}(k)\right]^{T}\end{array}\right.$ 
where $N_{j}$, as described for the utility grid and PV, is the diagonal identity matrix with three columns that affect physical the energy demand i.e. $j=1,2$, and 4.

- The BESS constraint is the charging and discharging of the energy of the device. As Eqs. (11) - (12) define it, simultaneous charging and discharging of the BESS is prohibited. This battery storage constraint is expressed by equation (41).

$\left\{\begin{array}{l}M_{5_{4_{i}}}=\left[N_{j_{i}}\right]^{T} \\ \gamma_{5_{4_{i}}}=[0]^{T}\end{array}\right.$

where $N_{j_{i}}$ has four columns $(j=4)$, but it is an identical diagonal vector of either $i=4$ (column) in charging process other elements are null or $i=3$ (column) in discharging process. From Eqs. (14) - (15), $M_{5_{4_{c}}}=[01-10], \gamma_{5_{4_{\mathrm{c}}}}=\left[E_{D}(k) / \eta_{\text {inv }}\right]$ and $\left.M_{5_{4_{d}}}=\left[\begin{array}{lll}0-1 & 0-1\end{array}\right], \gamma_{5_{4_{\mathrm{d}}}}=\left[E_{D} k\right) / \eta_{i n v}\right]$ could added during charging and discharging processes of battery respectively.

The system constraint is, therefore, the computation of Eqs. (33) - (41). The compact form of system constraint is defined as an inequality system matrix where the dimension is the function of the control signal and the number of constraints that the system that the system design can support. From Fig. 3, the adaptive MPC design system constraints can be rewritten as:

$$
M E(k) \leq \gamma
$$

whereas $M$ and $\gamma$ are respectively the row vector of each $M_{i_{j}}$ and $\gamma_{i_{j}}$ from Eq. (33) to Eq. (41) as described in [6]. 


\subsection{Adaptive TOU-MPC algorithm}

The implementation of the designed approach consists of creating the algorithm instruction as described in [7, 53]. Considering the discrete state space model Eqs. (22), the system performances index Eq. (31) and the compact system constraints Eq. (42) which is a function of Eq. (33) to (41), therefore an adaptive TOU- MPC algorithm instructions can be devised. The optimization strategy involves the execution of the following steps:

1. If the bulk electricity tariff as described in Table 1 is equal to:

- Off-peak value, execute the Off-Peak MPC;

- Standard value, go to the Standard MPC;

- Peak value, compile the Peak MPC.

2. For a given sample of time $k$, determine the control horizon and predictive horizon of the system.

3. Compute the optimization strategy through the performance index as defined in (31), which consist

4. Trough the MPC receding horizon control strategy determine the optimum system inputs as described in (23).

5. Find the optimal system outputs which are defined in Eq. (30).

6. Go to the next sample $k=k+1$, while updating the system inputs, outputs and states, and then repeat the instructions 1 to 5 until $k=N_{P}$.

\section{SIMULATION AND RESULTS}

From Table 1 and Fig. 1(a)-(b), due to the random variation of solar energy resources, it can be demonstrated that the electricity tariff and plane of array irradiance can affect negatively or positively the integration renewable energy resources into the electrical system. The PV array is therefore designed as per the season of the year which defines the variation of solar radiation or/and irradiance (Fig. 1(a)-(b)), and the peak of load demand (Table 1). There are several important factors to take into consideration when a PV array is integrated into a given electrical system as depicted in Fig. 2. The location's geometric characteristics, the difference between system energy demand and the energy from the uncontrollable load (target of the energy demand), the energy storage system that has to cover the random variation of solar energy resources are also considered as primary factors in selecting a solar generating system. 
It is observed that from Fig. 1(a)-(b) two-axis tracking can be chosen for optimal energy generation that can cover the total energy supply of the load. For a commercial system application, the parameters of the PV array are defined in Table 2 [43]. The choice of energy storage device is based on its power rating and its hourly energy rate. Furthermore, charge and discharge efficiency, the state of charge and depth of discharge (the inverse of the state of charge Eq. (6)) of the battery are also the key parameters considered when selecting a battery energy storage. Table 2 describes the PV array parameters and the critical parameters of the energy storage used for an optimal energy supply. In Table 2 , it is important to notice that the continuous discharge (CD) of the battery is set at rated power.

The proposed energy management approach is applied to a grid connected end consumer with onsite renewable energy sources under a real-time electricity tariff with the objective of minimising grid energy cost and maximising the use of renewable energy resources. Thus, the system design from Eqs. (22) to (28) combines with the real-time electricity tariff and implemented as described in [6,7]. The proposed MPC system with the integration of renewable energy (PV array and ESS) into the grid is simulated in the context of a South African city of Tshwane as presented in Table 1. Consequently, the restriction parameters of the designed system are chosen to function with TOU electricity tariff. Table 3 defines the relevant parameters used for the implementation of the MPC system design. It is also essential to note that the designed system has one hour as a sample of time to test the performance of the proposed approach in real-time.

Table 2 PV array and ESS parameters

\begin{tabular}{cccc}
\hline \hline \multicolumn{4}{c}{ PV System Specifications for commercial usage } \\
\hline \hline DC System Size (kW) LP/HP & $350 / 450$ & System Losses & 0.14 \\
Module Type & Standard & Inverter Efficiency & 0.96 \\
Array Type & 2-Axis Tracking & DC to AC Size ratio & 1.1 \\
Array Tilt & $25.7^{\circ}$ & Capacity Factor & 0.245 \\
Array Azimuth & $0^{\circ}$ & PV price (Rand/kWh) & R0.62 \\
\hline \hline Battery Storage System Specifications (red 30-150) \\
\hline \hline Rated Power (kW) & 30 & Capacity (kWh) & 150 \\
Peak Power (Kw) & 60 & CD at rated power (h) & 5 \\
Charging efficiency & 0.8 & Discharging efficiency & 1 \\
SOC maximal & 100 & SOC minimal & 10 \\
\hline \hline
\end{tabular}

\subsection{Simulation}


The energy system design of this commercial building is analysed under two scenarios as described in Table 3. It worth noting that all minimum values of the constraint are set to zero. All these cases are calculated by using the system parameters and specification defined in Tables 1, 2, and 3. However, the system constraint Eq. (41) is automatically shifted from charge to discharge mode in the response to solar PV output's seasonal variations. This period is mostly from $5 \mathrm{pm}$ to $6 \mathrm{pm}$ for L-P and H-P respectively. Other constraint values such as of Eqs. (35) and (37) derive from Table 3 and their computational relationship. Figures. 3 to 8 present the simulations results of the advanced model.

Table 3 Simulation Parameters (constraints)

\begin{tabular}{ccccccc}
\hline \hline System & Off-Peak & Standard & Peak & Off-Peak & Standard & Peak \\
Parameters & L-P & L-P & L-P & H-P & H-P & H-P \\
\hline \hline$r_{w}$ & 1 & 1.70223 & 2.5 & 1 & 1.940209 & 3 \\
$E_{1 \text { max }}(\mathrm{kWh})$ & 70 & 70 & 70 & 80 & 80 & 80 \\
$E_{2 \text { max }}(\mathrm{kWh})$ & 350 & 350 & 350 & 450 & 450 & 450 \\
$E_{3 \text { max }}(\mathrm{kWh})$ & 120 & 120 & 120 & 120 & 120 & 120 \\
$E_{4 \text { max }}(\mathrm{kWh})$ & 15 & 80 & 80 & 20 & 20 & 20 \\
$\Delta E_{1 \text { max }}(\mathrm{kWh})$ & 20 & 40 & 40 & 20 & 50 & 50 \\
$\Delta E_{2 \text { max }}(\mathrm{kWh})$ & 40 & 40 & 40 & 50 & 50 & 50 \\
$\Delta E_{3 \max }(\mathrm{kWh})$ & 120 & 120 & 38 & 120 & 120 & 25 \\
$\Delta E_{4 \max }(\mathrm{kWh})$ & 40 & 40 & 40 & 50 & 50 & 50 \\
\hline \hline
\end{tabular}

\subsubsection{Scenario 1}

In this case, the MPC-based energy management system of a commercial building as described in Fig. 2 is simulated in low demand period. This entails an analysis of the electrical system behaviour during the low period demand where all system parameters and specifications are considered as described in Tables 2-3. The solar PV output in this season is set at $350 \mathrm{~kW}$ DC system, but other specifications do not change according to L-P parameters and plane of array irradiance that is depicted in Fig. 1(a). Figures 3 and 4 show the computation of the system inputs, the energy demand target and the solar PV energy supply. It is observed that the designed system is robust enough to respect all system constraints. From Fig. 3, it can be seen that the system behaviour is optimally following the set target.

The output of the system that is mostly based on the cost of electricity from the utility grid during the system simulation is depicted in Fig. 5. However, this is the comparison between the output from a system designed by using an MPC system to manage the reference electricity Page $\mathbf{2 7}$ of $\mathbf{3 8}$ 
cost of energy that the customer wants to pay the utility and the cost of energy, with one without the system managing. In fact, there are some differences between the target and the optimal charge at 7-9 am in the morning and 5-6 pm. However, from the consumer point of view, it can be seen that the cost electricity is optimally shrinking in target value. Thus, Fig. 5 depicts an acceptable optimal result by reducing the cost of energy of a commercial building in a low demand period when the MPC managing system is embedded.

The simulation results of the system output based on the utility grid's energy cost are shown in Fig. 5. This is the comparison between the output of a system designed using an MPC system to manage the reference utility grid energy cost and the baseline energy cost; that is, the energy cost without deployment of the MPC-based management system. As shown, there are some differences between the target and the optimal cost at 7:00-9:00 am in the morning and 5:00-6:00 pm. However, from the consumer point of view, the target value of the electricity cost is optimally reduced. Figure 5 shows an acceptable optimal result by reducing the cost of energy of a commercial building in a low demand period when the MPC-based energy management system is embedded.
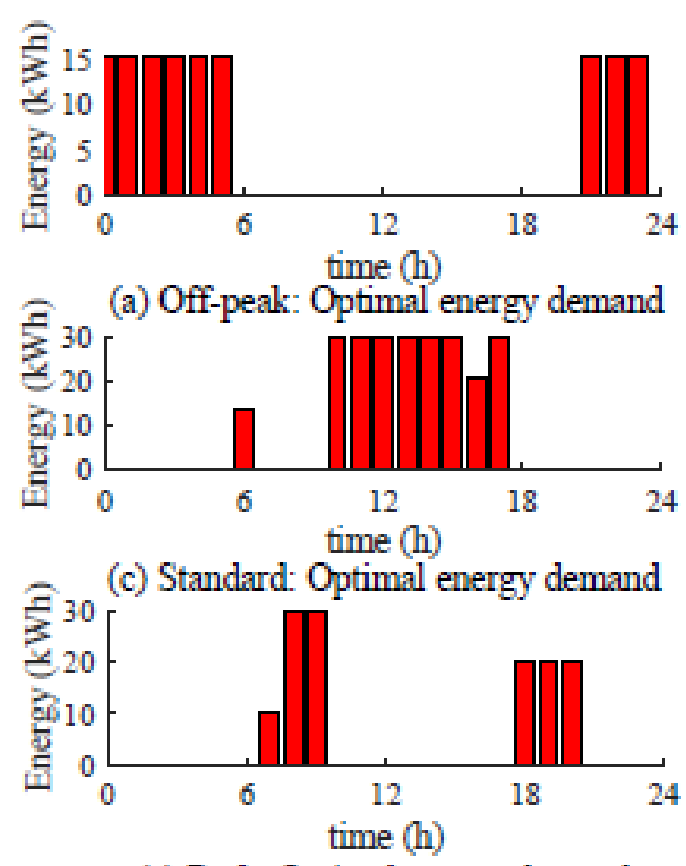

(e) Peak: Optimal energy demand

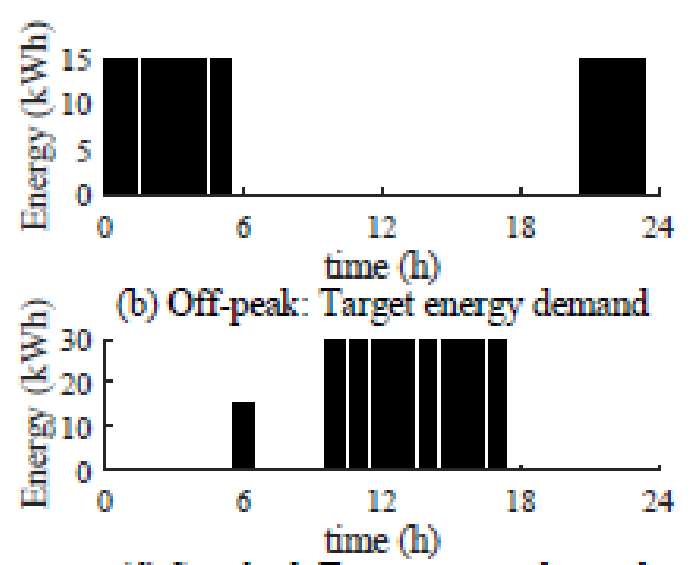

(d) Standard: Target energy demand

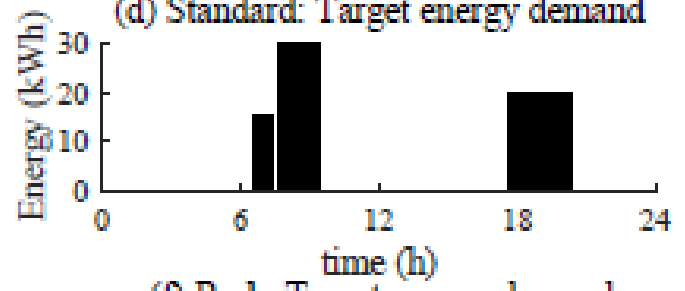

(f) Peak: Target energy demand

Fig. 3. Optimum demand and reference of the energy from the utility grid for L-P. 


\subsubsection{Scenario 2}

The high demand period, that is, the winter season in South Africa has a negative impact on the performance of solar PV. Figure 1 (b) shows the plane of array irradiance of the winter period where there are minimal differences between all PV technology. This is one of the reasons for choosing a two-axis tracking system to analyse the system behaviour when the adaptive TOUMPC managing system is implemented. As shown in Fig. 1(a), all types of array during this period can give the optimal results of the system design. During the high demand period, the same solar PV array model that is used in low demand can be considered, but its DC system size is augmented to $100 \mathrm{~kW}$. The main objective of the system design is to meet the system load demand in the most economical way. Simulation results of the MPC-based energy management system in winter are shown in Figures $6-8$.

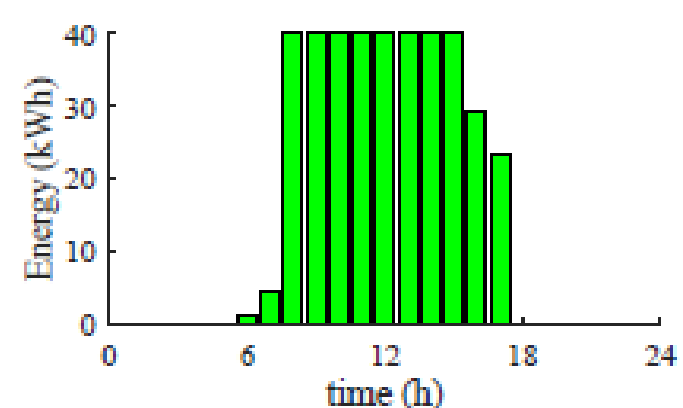

(a) Optimum energy from PV array

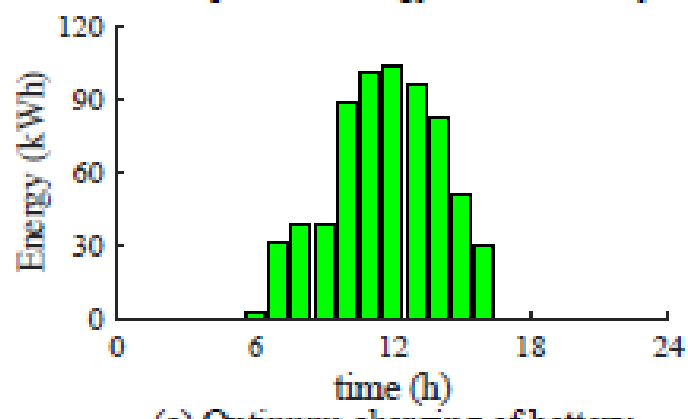

(c) Optimum charging of battery

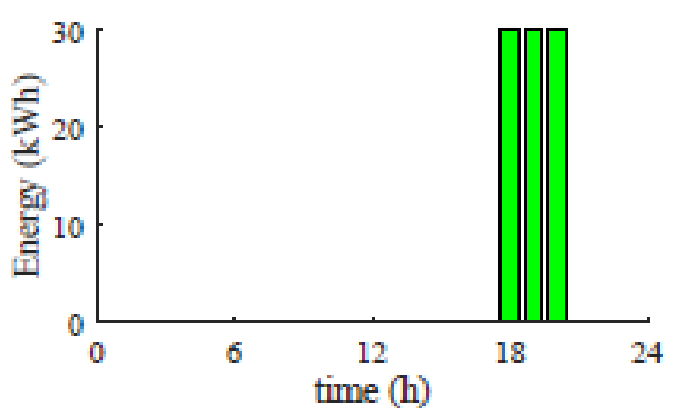

(b) Optimum discharging of battery

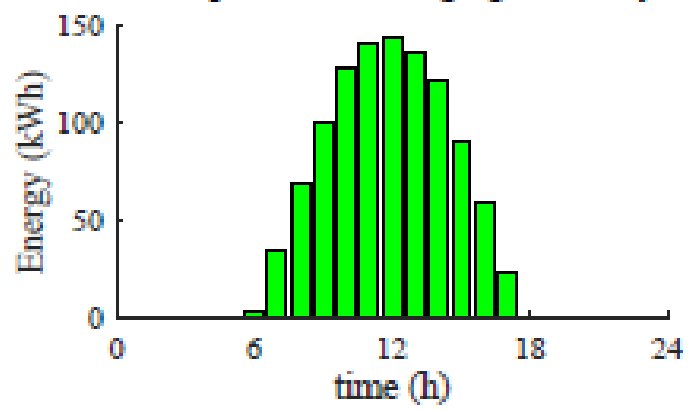

(d) Energy generation by PV array

Fig. 4. The flow of renewable energy resources (PV array) for L-P. 


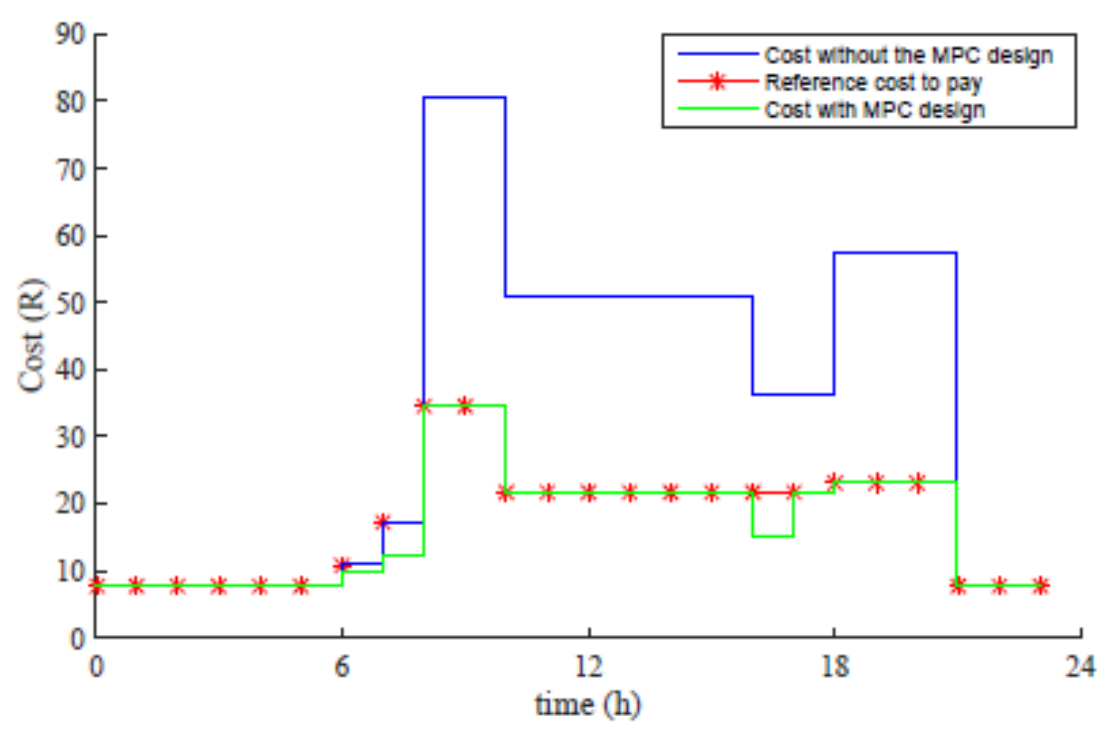

Fig. 5. The different electricity costs from the utility grid for L-P.

Figure 6 shows that the MPC system design in winter also optimally follows the system constraints and the energy demand target. Moreover, like the low demand period, from Table 1 and Figure 6, it is observed that a change in the energy demand can reduce the power to less than the set target of the demand. While the system constraints and parameters are respected, the solar energy resource is performing optimally as shown in Fig. 7. During the high demand period, the electricity cost is also optimally reduced for consumers by following the set cost target when the MPC-based energy management system is applied to a commercial building in winter.
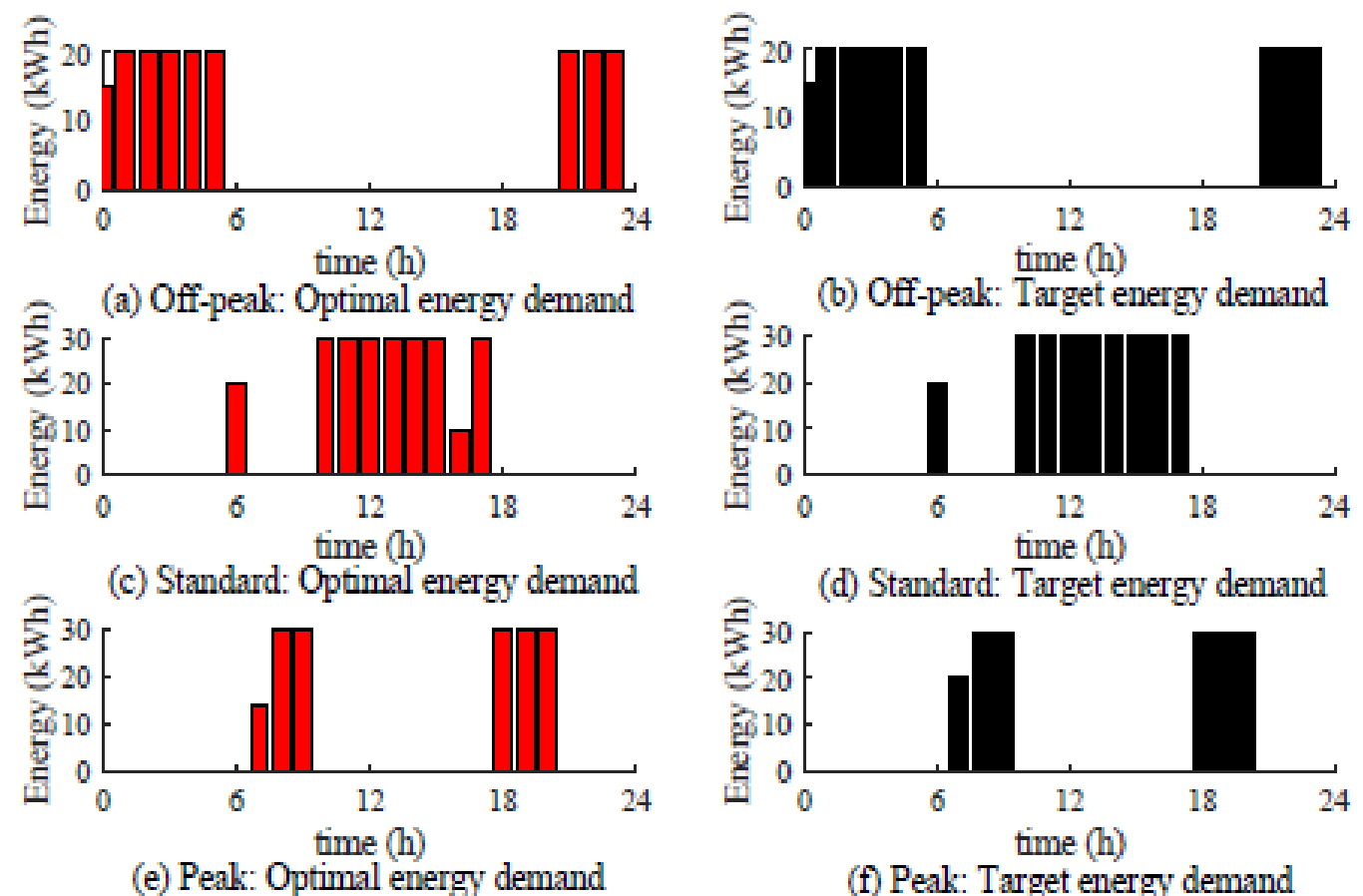

(f) Peak: Target energy demand 
Fig. 6. Optimum demand and reference of the energy from the utility grid for H-P.

\subsection{Results discussion}

Through the simulation analysis, it is demonstrated that the integration of a solar energy generating system with the ESS assures the optimal cost of electricity that can follow the setting energy demand target. In fact, the improvement of the optimal energy charge can, therefore, be compared to the setting targets to test the accuracy of the MPC-based management system design. This approach is demonstrated from Figures 3-8. It is also observed that there are a few differences between the reference and the optimal energy cost that must follow the target. This observation is made after two similar periods for both L-P and H-P; firstly, when the system must shift between adaptive MPC as described in Fig. 2, and then when the energy demand change as shown in Table 1 with the optimal results in Figs. 3 and 6. The designed model is robust to satisfy the system constraints and to minimise the grid energy cost by following the set energy demand target. Table 4 describes the daily energy cost of network analysis in each period.

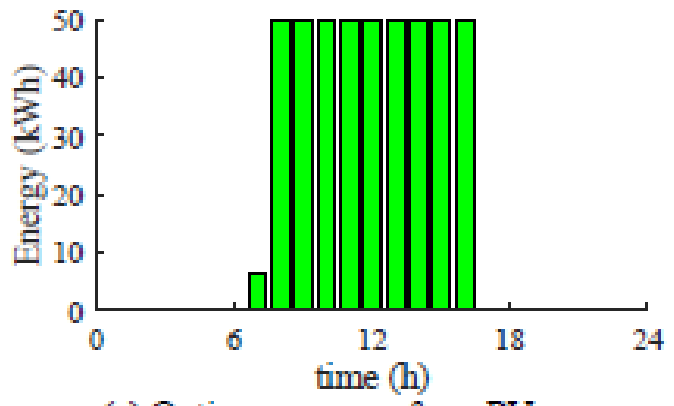

(a) Optimum energy from PV array

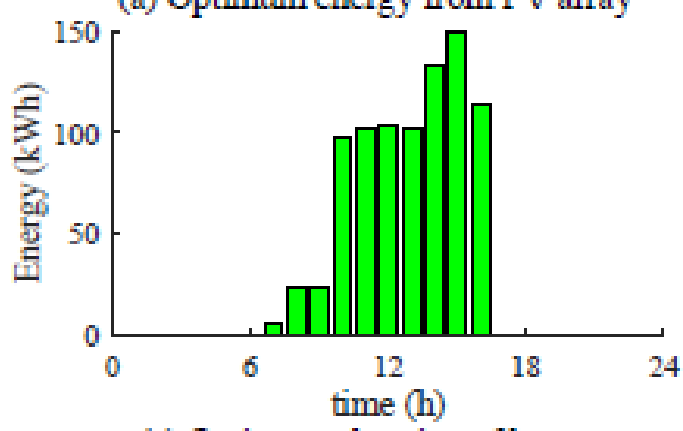

(c) Optimum charging of battery

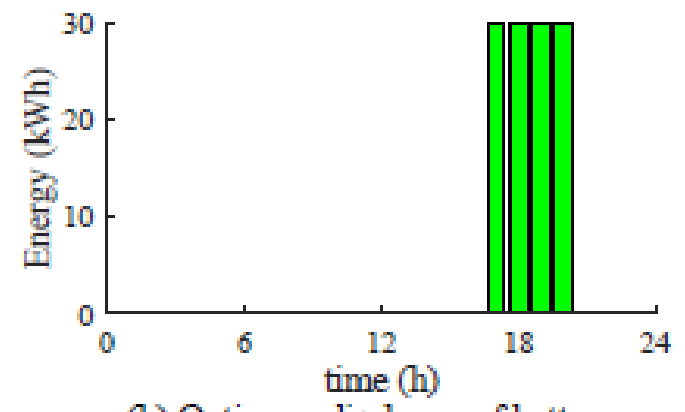

(b) Optimum discharge of battery

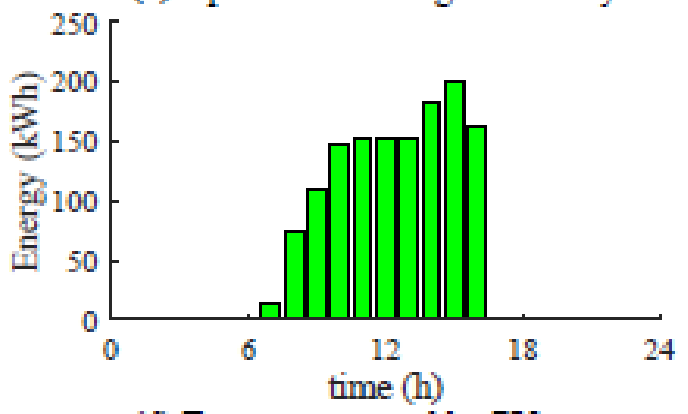

(d) Energy generated by PV array

Fig. 7. The flow of renewable energy resources (PV array) for H-P. 


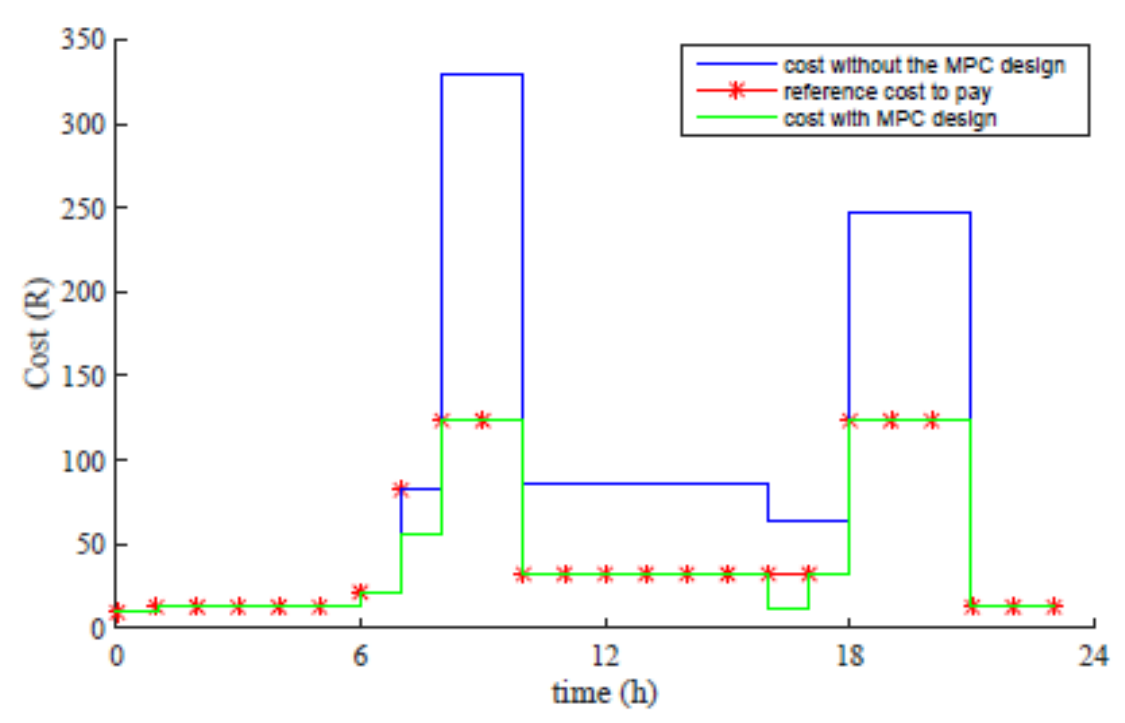

Fig. 8. The different electricity cost from the utility grid for H-P.

Table 4 Different daily energy costs

\begin{tabular}{|c|c|c|c|}
\hline $\begin{array}{l}\text { Cost of energy to pay the Utility } \\
\text { grid in Rand }\end{array}$ & $\begin{array}{c}\text { Low demand } \\
\text { period }\end{array}$ & $\begin{array}{l}\text { High demand } \\
\text { period }\end{array}$ & $\begin{array}{l}\text { Difference } \\
\text { H-P vs L-P }\end{array}$ \\
\hline Without the MPC system & R808.2 & R2254.3 & R1446.1 \\
\hline Target or Reference & $\mathrm{R} 409.5$ & $\mathrm{R} 1086.2$ & $\mathrm{R} 676.7$ \\
\hline With the MPC system managing & R396.5 & $\mathrm{R} 1038.6$ & R642.1 \\
\hline
\end{tabular}

The weighted coefficient plays an important role in the optimization process. It can negatively or positively affect the performance index of the system design. The choice of this factor depends mostly on the variation of demand and real-time electricity pricing in the case of TOU-tariff as described in Table 3. The observation that can be made from this is that when the price of electricity and the demand, the weight coefficient also increases. Tables 3 describe the difference values of the tuning parameter during off-peak, standard, or peak periods of L-P and L-H.

From PV array types, as 2-axis system is used to compute this system design optimally, it can be observed that there was a difference of $100 \mathrm{~kW}$ DC power rating of the solar energy generating system between L-P and H-P computations. However, the selected daily plane of array irradiance during the lowest demand period of all PV technologies are nearly equal. The 
system can also use a fixed axis PV of the total used DC power during the winter for both demand periods. The solar energy generating system is integrated as an optimal strategy for both L-P and L-H when it is about to supply the energy demand and to charge the BESS. The discharging process of the BESS is optimal following the system design and constraints. It is demonstrated by the start time of discharging process which begins only after the end of solar energy generation as it is depicted in Figures 5 and 8. Due to the difference of solar irradiance of each period, it is also important to notice that the PV energy generating system has a different starting and ending point for each season (L-P and H-P).

From Table 4, the sum of system outputs when the adaptive TOU-MPC managing system is implemented is compared with the set target and the cost savings. The optimization of electricity cost by using the proposed strategy is $49.059 \%$ of the total energy demand of the electrical system in low demand period. The same output of the system in high demand period is reduced to $46.072 \%$ of total energy demand. With a target of $50.688 \%$ and $48.183 \%$ of electricity to pay in L-P and H-P respectively, the system approach operated to minimise the grid energy cost. It was also observed that when the TOU-MPC model is deployed under real-time electricity tariff for a commercial building's application, the difference between the set references and the optimal grid energy cost is $1.609 \%$ and $2.111 \%$ in L-P and H-P respectively. These results prove that this approach satisfies the system requirement.

\section{CONCLUSION}

The proposed strategy presents an adaptive TOU-MPC managing system design in a realtime electricity pricing environment, which consists of integrating a solar energy generating and energy storage system into an isolated power grid. It has been observed that the system design is optimally efficacy and that the proposed strategy achieved a good performed by managing the energy consumption by prioritising some loads while controlling the power supply as a function of the demand. This approach gave the consumer an opportunity to maintain the cost of electricity to pay and to decide on the amount of the energy usage. The performance index of the system design was evaluated in conjunction with low and high demand periods. It was found that the proposed approach was effective thus confirming that the total cost of electricity can be reduced to suit the customer needs. It is therefore expected that the proposed approach can be seen as a benchmark to develop a real-time electricity pricing optimisation in any sector that has fair atmospheric and environmental conditions for renewable energy integration. 
Future work will focus on designing a system that accommodates demand from different customers with the same bulk point of power supply which includes both the utility grid and a renewable energy generating system. A system design that takes into consideration the opportunity cost will also be considered as a future study case.

\section{REFERENCES}

[1] D. Loveday, and G. Virk, "Artificial intelligence for buildings," Applied Energy, vol. 41, no. 3, pp. 201-221, 1992.

[2] A. Fawaz, R Berthier, and W. Sanders, "A response cost model for advanced metering infrastructures”, IEEE Trans. Smart Grid, vol. 7, no. 2, pp. 543-553, 2016.

[3] K. Weranga, S. Kumarawadu, and D. Chandima, "Smart metering design and applications," Singapore: Springer, 2014.

[4] A. Shawkat, "Smart grids: opportunities, developments, and trends", Springer, 2013.

[5] A. Mohsenian-Rad, and A. Leon-Garcia, "Optimal residential load control with price prediction in real-time electricity pricing environments", IEEE Trans. Smart Grid, vol. 1, no. 2 , pp. $120-133,2010$.

[6] N.T. Mbungu, R. Naidoo, R. C. Bansal, M. Bipath, "Smart SISO-MPC based energy management system for commercial buildings: Technology trends", IEEE Future Technologies Conference (FTC), San Francisco, USA, pp. 750-753, Dec. 6-7, 2016.

[7] N. T. Mbungu, R. M. Naidoo, and R. C. Bansal, "Real-time electricity pricing: TOU-MPC based energy management for commercial buildings", 8th International Conference on Applied Energy, Beijing, China, vol. 105, pp. 3419-3424, May 2017.

[8] L. Gelazanskas, and K. A Gamage, "Demand side management in smart grid: A review and proposals for future direction", Sustainable Cities and Society, vol. 11, pp. 22-30, 2014.

[9] K. O. Aduda, T. Labeodan, W. Zeiler, and G. Boxem, "Demand side flexibility coordination in office buildings: a framework and case study application", Sustainable Cities and Society, vol. 29, pp. 139-158, 2017.

[10] N. T. Mbungu, R. Naidoo, R. Bansal, M. Bipath, "Optimal single phase smart meter design”, The Journal of Engineering, vol. 2017, no. 13, pp. 1220-1224, 2017. 
[11] F. Sehar, M. Pipattanasomporn, and S. Rahman, "Integrated automation for optimal demand management in commercial buildings considering occupant comfort", Sustainable Cities and Society, vol. 28, pp. 16-29, 2017.

[12] M. Al-Nory, M El-Beltagy, “An energy management approach for renewable energy integration with power generation and water desalination”, Renewable Energy, vol. 72, pp. 377-385, 2014.

[13] M. Farrokhifar, F. Momayyezi, N. Sadoogi, and A. Safari, "Real-time based approach for intelligent building energy management using dynamic price policies”, Sustainable Cities and Society, vol. 37, p. 85-92, 2018.

[14] N.T. Mbungu, R. Naidoo, R. C. Bansal, M. Bipath, "Grid integration and optimization through smart metering”, 2nd SAIEE Smart Grid Conference, Midrand, South Africa, 1921 Sep. 2017.

[15] N. Nezamoddini, and Y. Wang, "Real-time electricity pricing for industrial customers: Survey and case studies in the United States", Applied energy, vol. 195, pp. 1023-1037, 2017.

[16] A. Sheikhi, M. Rayati, and A. M. Ranjbar. "Dynamic load management for a residential customer; reinforcement learning approach." Sustainable Cities and Society, vol. 24, pp. 42-51, 2016

[17] M. Roustai, M. Rayati, A. Sheikhi, and A. Ranjbar, "A scenario-based optimization of smart energy hub operation in a stochastic environment using conditional-value-at-risk," Sustainable Cities and Society, vol. 39, pp. 309-316, 2018.

[18] L. Gelazanskas, and K.A. Gamage, "Demand side management in smart grid: A review and proposals for future direction", Sustainable Cities and Society, vol. 11, pp. 22-30, 2014.

[19] N. Javaid, M. Naseem, M. B. Rasheed, D. Mahmood, S. A. Khan, N. Alrajeh, and Z. Iqbal, "A new heuristically optimized home energy management controller for smart grid", Sustainable Cities and Society, vol. 34, pp. 211-227, 2017.

[20] H. Wang, H. Fang, X. Yu, and S. Liang, "How real time pricing modifies Chinese households' electricity consumption”, Journal of Cleaner Production, vol. 178, pp. 776790, 20 March 2018.

[21] A. Nilsson, P. Stoll, and N. Brandt, "Assessing the impact of real-time price visualization on residential electricity consumption, costs, and carbon emissions," Resources, Conservation and Recycling, vol. 124, pp. 152-161, 2017. 
[22] A. Rosin, S. Link, M. Lehtla, J. Martins, I. Drovtar, and I. Roasto, "Performance and feasibility analysis of electricity price-based control models for thermal storages in households", Sustainable Cities and Society, vol. 32, pp. 366-374, 2017.

[23] V. Kapsalis, and L. Hadellis, "Optimal operation scheduling of electric water heaters under dynamic pricing,” Sustainable Cities and Society, vol. 31, pp. 109-121, 2017.

[24] M. Razmara, R. Bharati, D. Hanover, M. Shahbakhti, S. Paudyal, and D. Robinett III, "Building-to-grid predictive power flow control for demand response and demand flexibility programs", Applied Energy, vol. 203, pp. 128-141, 2017.

[25] G. Bianchini, M. Casini, A. Vicino, and D. Zarrilli, "Demand-response in building heating systems: A Model Predictive Control approach”. Applied Energy, vol. 168, pp. 159-170, 2016.

[26] L. Li, S. You, C. Yang, B. Yan, J. Song, and Z. Chen, "Driving-behavior-aware stochastic model predictive control for plug-in hybrid electric buses", Applied Energy, vol. 162, pp. 868-879, 2016.

[27] A. Mirakhorli, and B. Dong, "Market and behavior driven predictive energy management for residential buildings," Sustainable Cities and Society, vol. 38, pp. 723-735, 2018.

[28] A. Buonomano, U. Montanaro, A. Palombo, and S. Santini, "Dynamic building energy performance analysis: A new adaptive control strategy for stringent thermohygrometric indoor air requirements", Applied Energy, vol. 163, pp. 361-386, 2016.

[29] J. Široký, F. Oldewurtel, J. Cigler, S. Prívara, "Experimental analysis of model predictive control for an energy efficient building heating system", Applied Energy, vol. 88, no. 9, pp. 3079-3087, 2011.

[30] N. T. Mbungu, R. Naidoo, R. Bansal, M. Bipath, "Optimisation of grid connected hybrid photovoltaic-wind-battery system using model predictive control design", IET Renewable Power Generation, vol. 11, no. 14, pp. 1760-1768, 2017.

[31] S. Zhang, R. Xiong, and F. Sun, "Model predictive control for power management in a plug-in hybrid electric vehicle with a hybrid energy storage system”, Applied Energy, vol. 185, pp. 1654-1662, 2015.

[32] E. M. Wanjiru, S. M. Sichilalu, and X. Xia, "Model predictive control of heat pump water heater-instantaneous shower powered with integrated renewable-grid energy systems", available online Applied Energy, 2017.

[33] V. Lešić, A. Martinčević, and M. Vašak. "Modular energy cost optimization for buildings with integrated microgrid", Applied Energy, vol. 197, pp. 14-28, 2017. 
[34] A. Di Giorgio, and F. Liberati, “ Near real time load shifting control for residential electricity prosumers under designed and market indexed pricing models", Applied Energy, vol. 128, pp. 119-132, 2014.

[35] T. Wakui, H. Kawayoshi, R. Yokoyama, and H. Aki, "Operation management of residential energy-supplying networks based on optimization approaches”, Applied Energy, vol. 183, pp. 340-357, 2016.

[36] M. Petrollese, L. Valverde, D. Cocco, G. Cau, and J. Guerra, "Real-time integration of optimal generation scheduling with MPC for the energy management of a renewable hydrogen-based microgrid", Applied Energy, vol. 166, pp. 96-106, 2016.

[37] A. Parisio, E. Rikos, G. Tzamalis, and L. Glielmo, "Use of model predictive control for experimental microgrid optimization”, Applied Energy, vol. 115, pp. 37-46, 2014.

[38] A. Zobaa, and R. C. Bansal, "Handbook of renewable energy technology", World Scientific Publisher Singapore, 2011.

[39] Y. Zhang, B. Liu, T. Zhang, and B. Guo, "An intelligent control strategy of battery energy storage system for microgrid energy management under forecast uncertainties" International Journal of Electrochemical Science, vol. 9, pp. 4190-4204, April 2014.

[40] T. Henerica, Z. Bing, and X. Xiaohua, "Switched model predictive control for energy dispatching of a photovoltaic-diesel-battery hybrid power system," IEEE Trans. Control System Technology, vol. 23, no. 3, pp. 1229-1236, May 2015.

[41] Tshwane, "2015/16 Medium term revenue and expenditure framework for city of Tshwane," Special council: May 2015.

[42] Department of Energy (DoE), "State of renewable energy in South Africa," Department: Energy, Republic of South Africa, 2015.

[43] http://pvwatts.nrel.gov/pvwatts.php, Solar Resource Data.

[44] H. Tazvinga, X. Xia, and J. Zhang, "Minimum cost solution of photovoltaic-diesel-battery hybrid power systems for remote consumers", Solar Energy, vol. 96, pp. 292-299, 2013.

[45] http://www.iec.ch/whitepaper/pdf/iecWP-energystorage-LR-en.pdf; Electrical Energy Storage IEC, white paper Online:

[46] H. Ibrahim, A. Ilinca, and J. Perron, "Energy storage systems - characteristics and comparisons," Renewable and Sustainable Energy Reviews, vol. 12, no 5, pp. 1221-1250, 2008.

[47] F. Luisa, S. Ramteen, "Handbook of clean energy systems," Wiley, vol. 5, 2015. 
[48] A. Castillo, and F. Gayme, "Grid-scale energy storage applications in renewable energy integration: A survey," Energy Conversion and Management, vol. 87, pp. 885-894, 2014.

[49] B. Grainger, G. Reed, A. Sparacino, and P. Lewis, "Power electronics for grid-scale energy storage," Proceedings of the IEEE, vol. 102, no. 6, pp. 1000-1013, 2014.

[50] M. Dürr, A. Cruden, S. Gair, and J.R. McDonald, "Dynamic model of a lead acid battery for use in a domestic fuel cell system," Journal of Power Sources, vol. 161, no. 2, pp. 1400$1411,2006$.

[51] J.P. Fossati, A. Galarza, A. Martín-Villate, and L. Fontán, “A method for optimal sizing energy storage systems for microgrids," Renewable Energy, vol. 77, pp. 539-549, 2015.

[52] B. Ai, H. Yang, H. Shen, and X. Liao, "Computer-aided design of PV/wind hybrid system," Renewable Energy, vol. 28, no. 10, 1491-1512, 2003.

[53] L. Wang, "Model predictive control system design and implementation using MATLAB®", Springer Science \& Business Media, 2009. 